\title{
تطوير التعليم في الجامعات السعودية من خلال تطبيق متطلبات إدارة الجودة الشـاملة في التعليم الجامعي
}

\author{
عروة محممد حمدان \\ أستاذ مساعد في عمادة الخدمات التعليمية- السنة التحضيرية في أبيار علي- جامعة طيبة- المملكة العربية السعودية مجدمان \\ orwahlor2000@yahoo.com
}

DOI: https://doi.org/DOI:10.31559/EPS2020.8.1.10

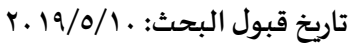

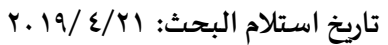

هدفت الدراسة إلى الكشف عن كيفية تطوير التعليم في الجامعات السعودية من خلال تطبيق متطلبات إدارة الجودة الشاملة في التعليم

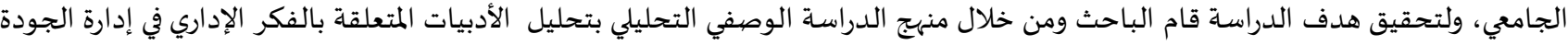

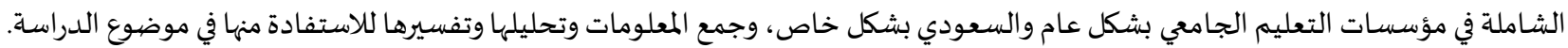

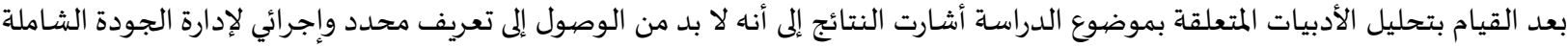

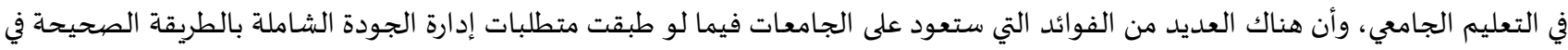

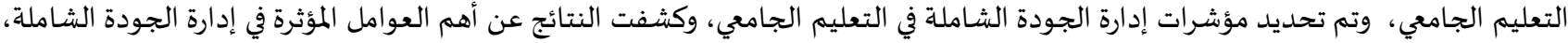

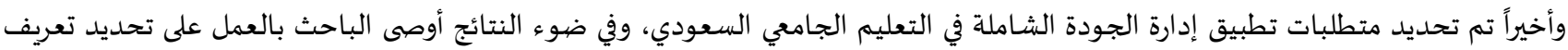

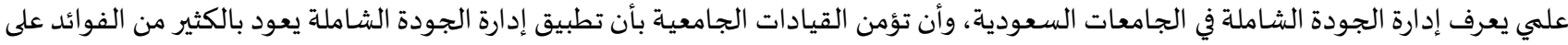

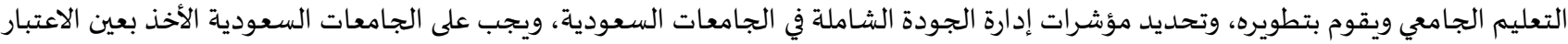

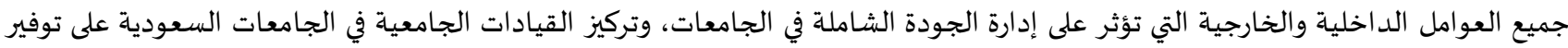
المتطلبات اللازمة لإدارة الجودة الشاملة لدهيا.

الكلمات المفتاحية: إدارة الجودة الشاملة؛ تطويرالتعليم الجامعي؛ المملكة العربية السعودية. (ㄷ) (1)

المقلدمة:

تُعتبر إدارة الجودة الشـاملة (Total Quality Management) إحدى المدارس الإدارية الحديثة نسبياً التي اجتاحت عالم الإدارة في دول أمريكا

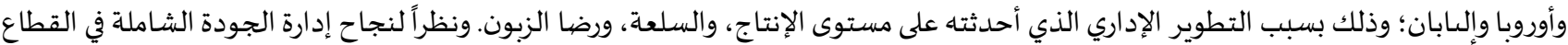

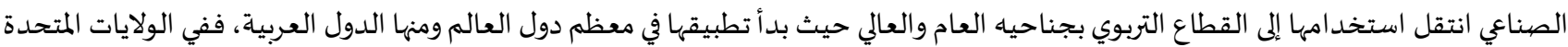

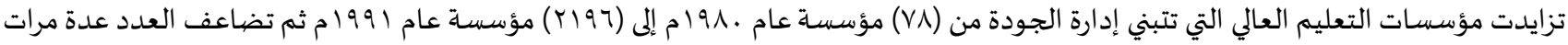

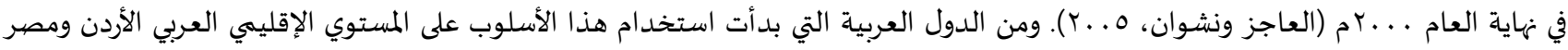

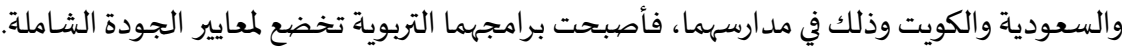

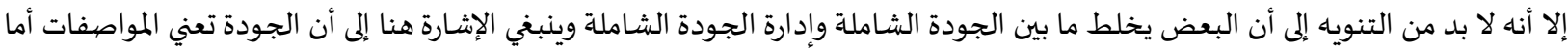

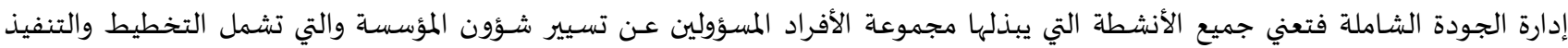
والتقويم، أو بعبارة أخرى هي عملية التنسيق التي تتم داخل المؤسسة بغرض التغلب على ما فيها من مشكلات، والمساهمة بشكل مباشر في تحقيق

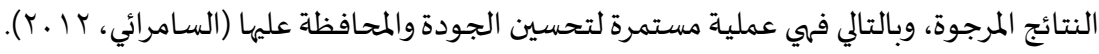


عرفت الجمعية الأمريكية لضبط الجودة (ASQC) والمنظمة الأوربية لضبط الجودة (EOQC) الجودة بأها "المجموع الكلي للمزايا والخصائص التي

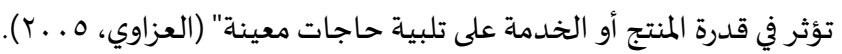

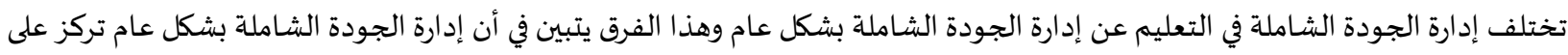

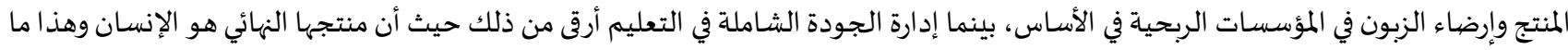
لا يقدر بثمن ولا بربح فتكون المسؤولية أكبر وأعمق.

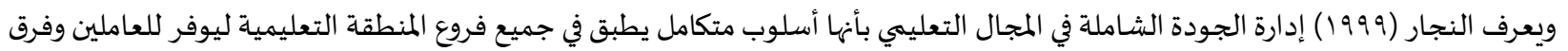

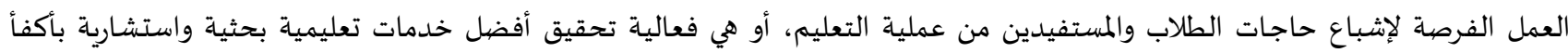
الأساليب وأقل التكاليف وأعلى جودة ممكنة. وهنا يجب أن نفرق ما بين إدارة الجودة الشاملة في التعليم وما بين إدارة الجودة منفردة في التعليم حيث أن إدارة الجودة التهارة الشاملة في التعليم أكبر

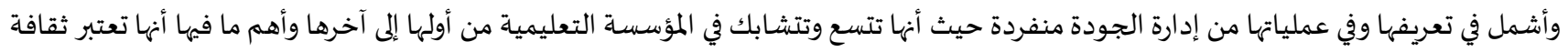

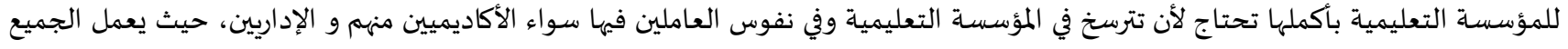

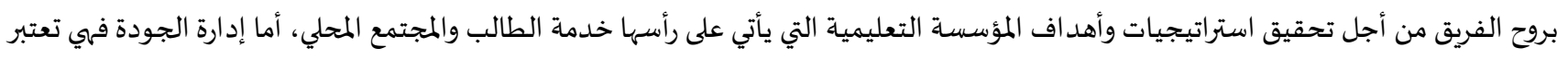

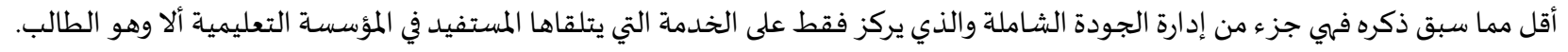

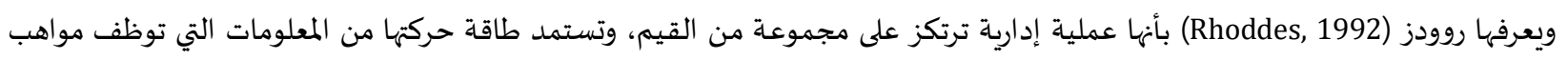

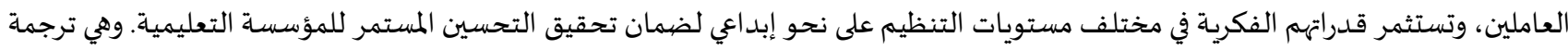

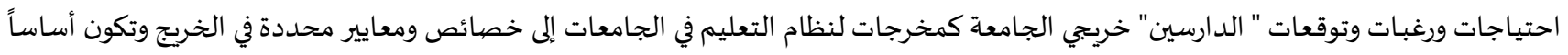
لتصميم برامج مع التطوير المستمر.

الدراسـات السابقة:

وردت الكثير من الدراسات السابقة حول مفهوم إدارة الجودة الشاملة في التعليم ومنها:

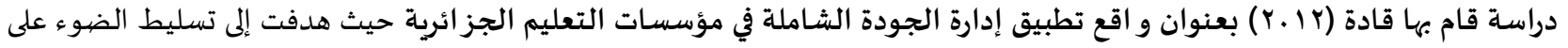

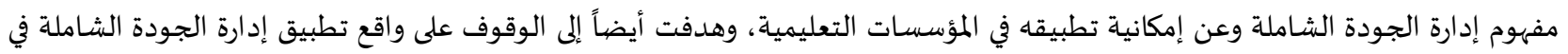

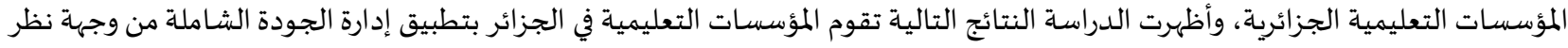

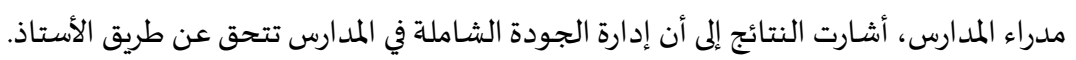

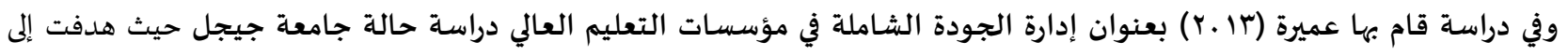

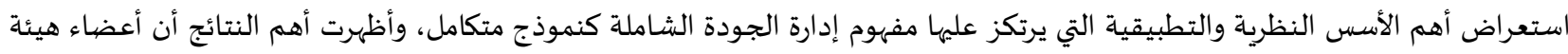

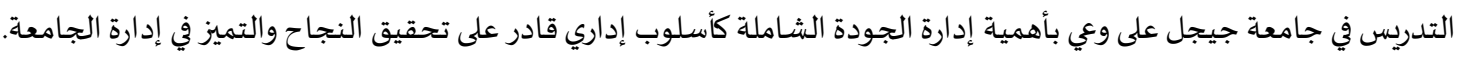

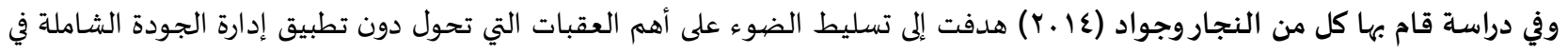

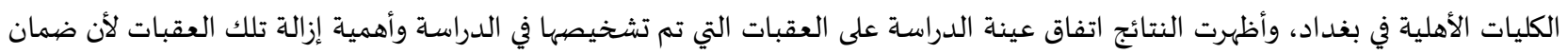

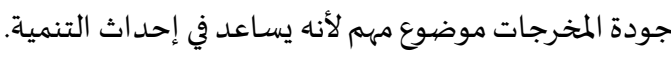

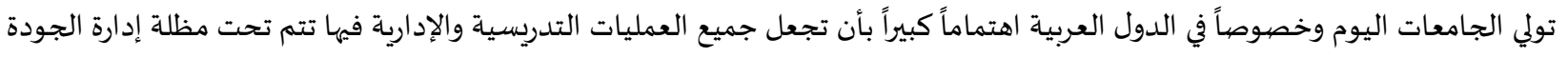

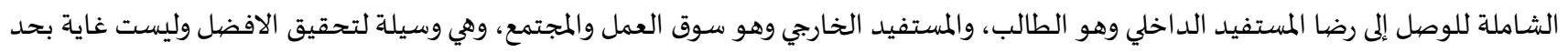

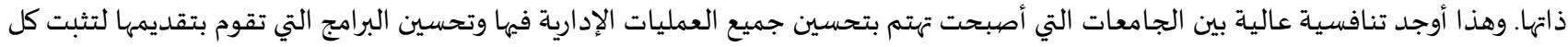

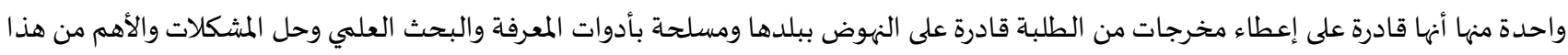

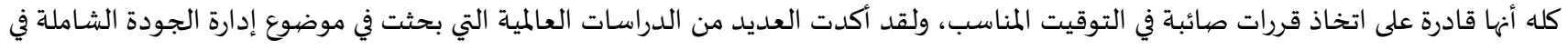

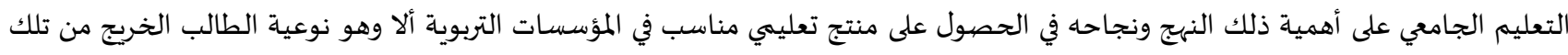

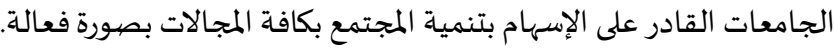

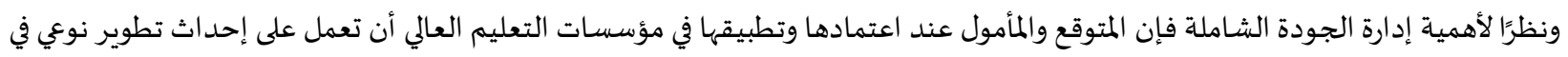

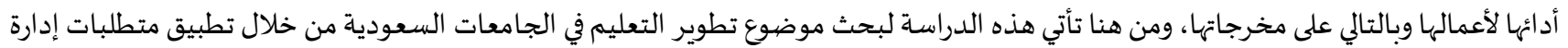
الجودة الشاملة في التعليم الجامعي. 
مشكلة الدراسـة وأسئلتها:

أثرت إدارة الجودة الشـاملة تأثيراً كبيراً في العديد من الجامعات العالمية والعربية وكان هذا التأثير إيجابياً على مختلف الصعد، مما يجعلها مرغوبة

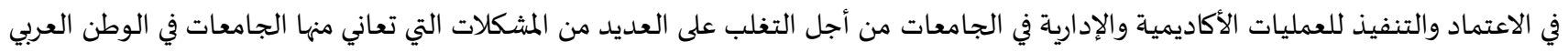

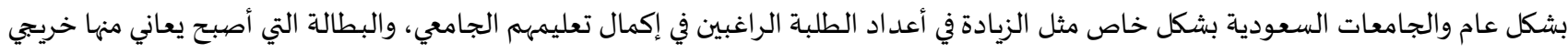

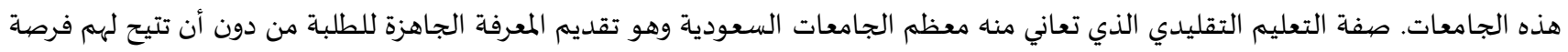

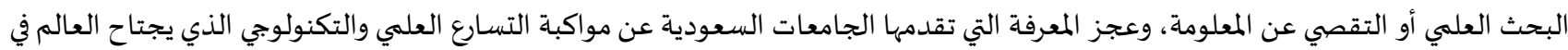
كل أنواع المعرفة. ومن هنا تأتي مشكلة هذه الدراسة في بحث كيفية تطوير التعليم في الجامعات السعودية من خلال تطبيق متطلبات إدارة الجودة الشاملة في التعليم الجامعي، وتتمثل مشكلة الدراسـة في الإجابة عن الأسئلة التالية:

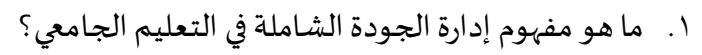

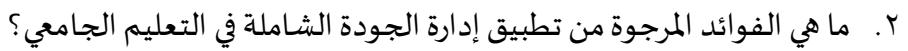

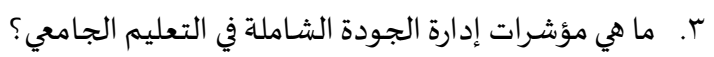

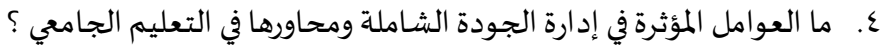

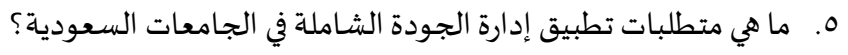

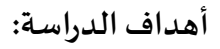

تسعى الدراسة لتحقيق الأهداف التالية: ا. . التعرف إلى مفهوم إدارة الجودة الشاملة في التعليم الجامعي وكيف أثر هذا المفهوم في إدارة الجامعات في السعودية.

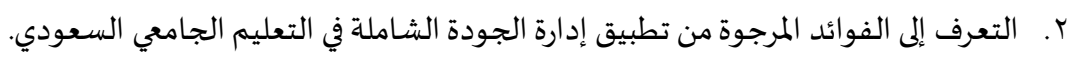

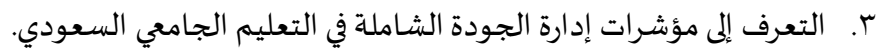

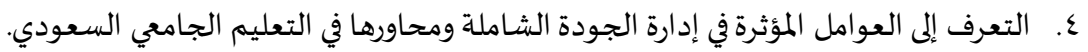

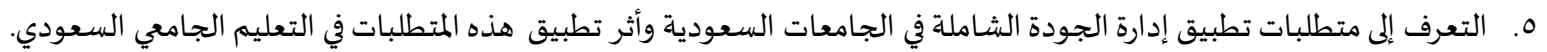

أهمية الدراسة:

تأتي أهمية هذه الدراسـة من أهها تهتم بالتركيز على موضوع إدارة الجودة الشاملة في التعليم الجامعي حيث أصبح هذا الموضوع أحد أبرز العناوين

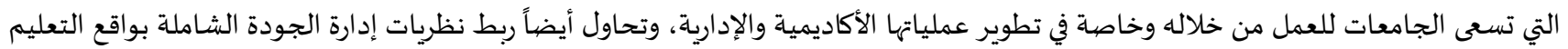

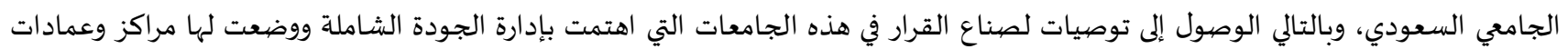

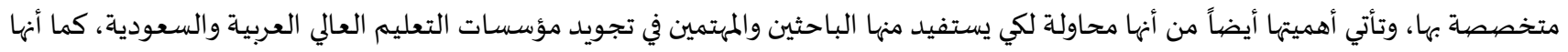
تسهم في محاولة تطوير التعليم الجامعي السعودي.

منهجية الدراسة:

استخدمت الدراسة المنهج الوصفي التحليلي الذي يعتمد على تحليل الأدبيات المتعلقة بالفكر الإداري في إدارة الجودة الشاملة في مؤسسات

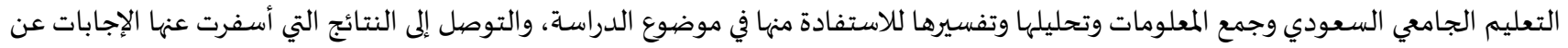
اسئلة الدراسة.

$$
\text { نتائج الدراسـة: }
$$

فيما يأتي عرض للنتائج التي توصلت إلها الدراسة في ضوء أسئلتها الخمسة التالية:

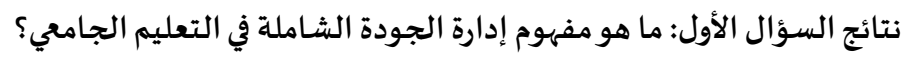

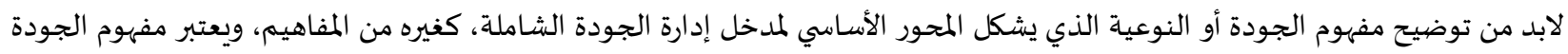

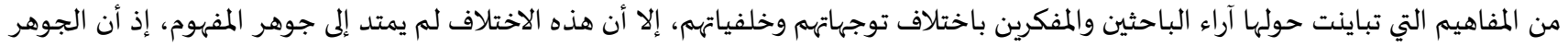
واحد يتمثل "بالسعي لتحقيق رضا العميل" (حمود، ج . . ب). 


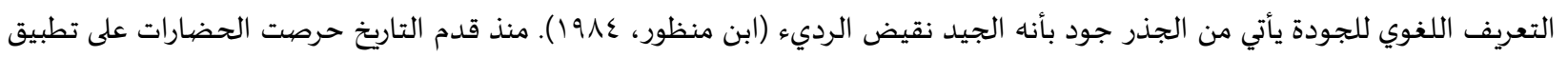

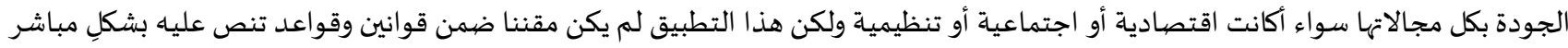

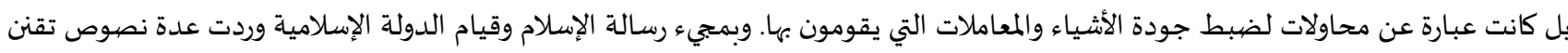

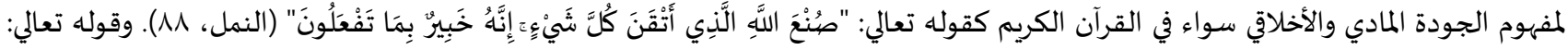

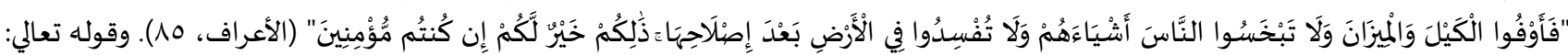

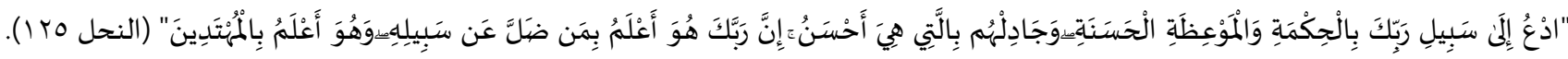

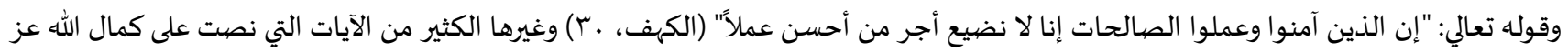

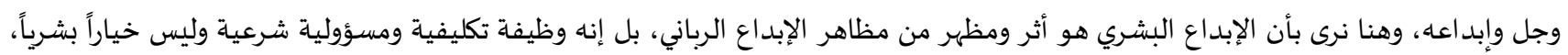

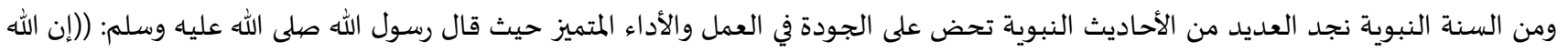

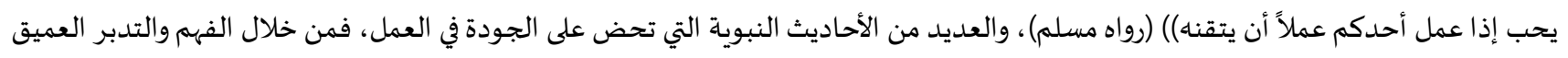

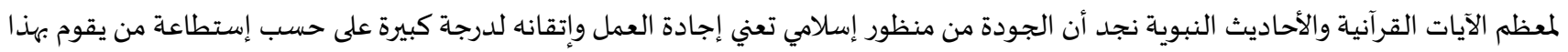

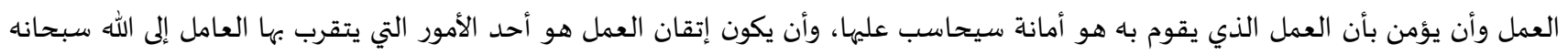
وتعالي، فالكثير من الألفاظ التي جاءت في القرآن والسنة تحمل نفس هذا الفا المعنى ومنها الإتقان، والإحسان.

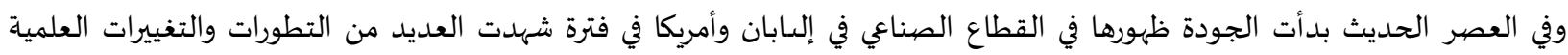

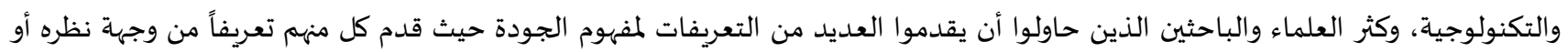

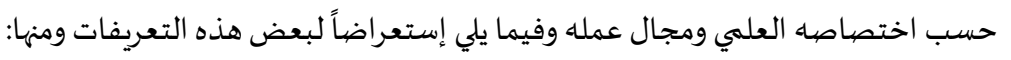

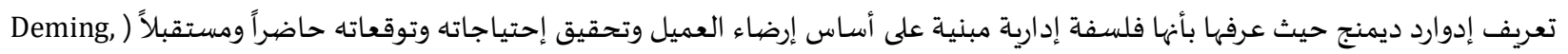

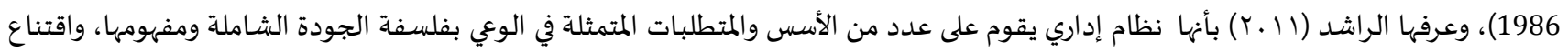

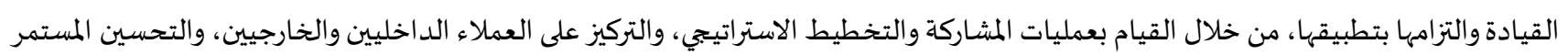

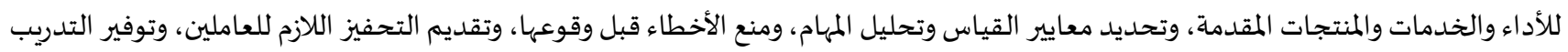

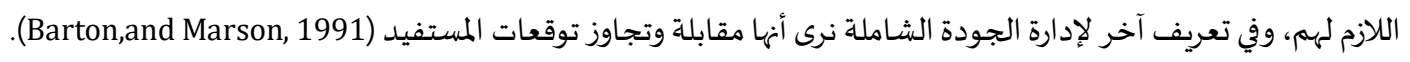

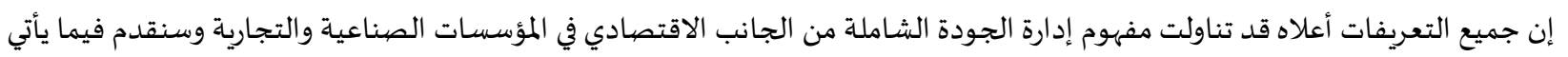

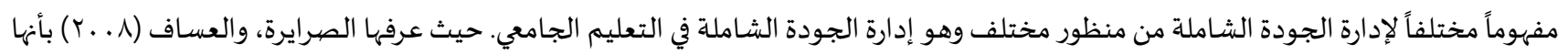

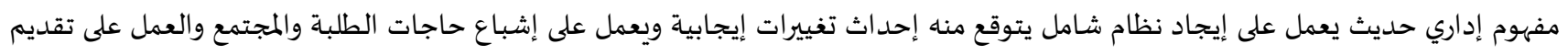

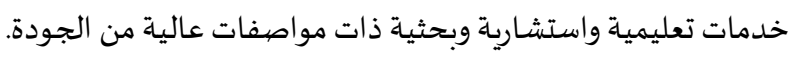

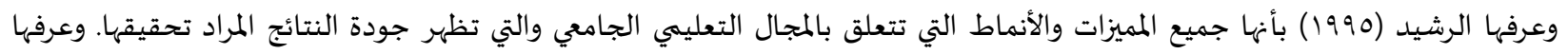

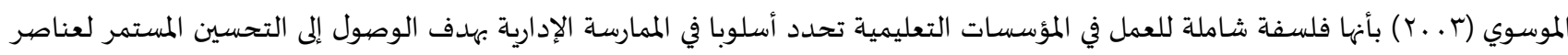

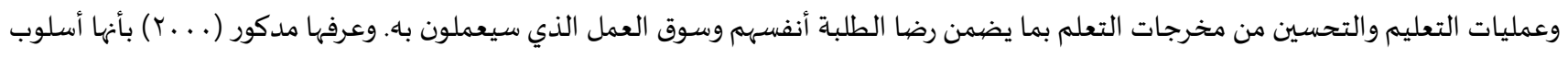

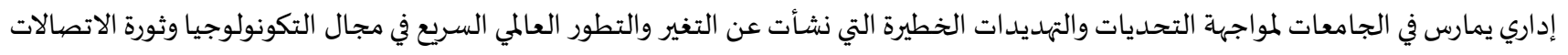

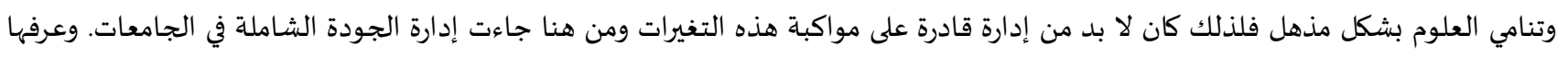

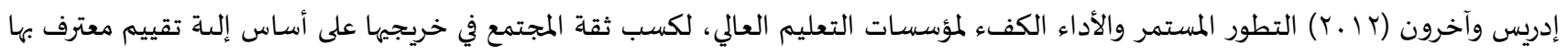

بعد استعراض هذه المجموعة من التعريفات لإدارة الجودة الشاملة في التعليم الجامعي نجد أن جميعها تجمع وتؤكد على أن الجامعات تسعى إلى الى المالي

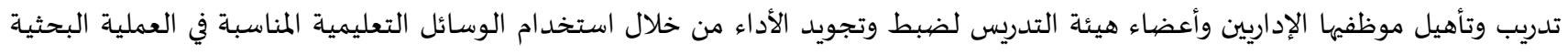

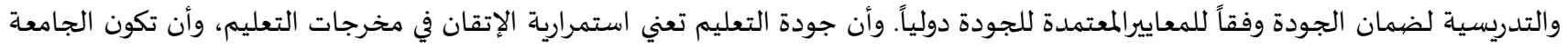

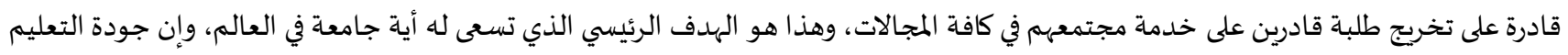

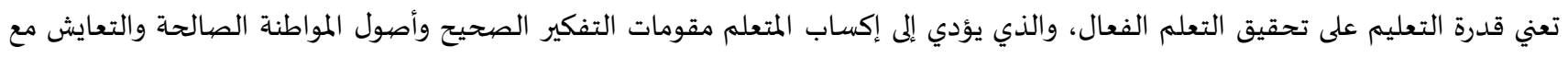

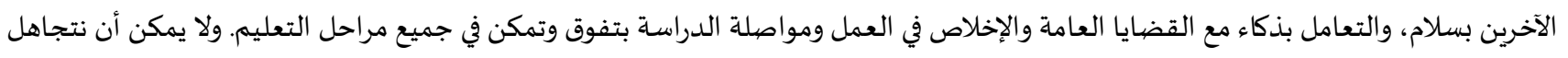

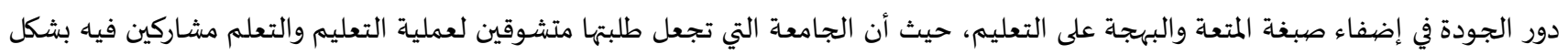

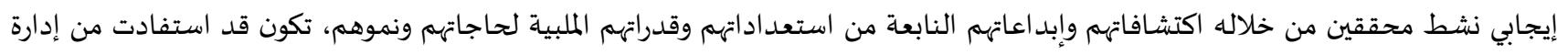


الجودة الشاملة استفادة عظيمة، ، لقد تعدت إدارة الجودة الشاملة في الجامعات مرحلة أن تكون خياراً من ضمن خيارات عدة بل أصبحت حاجة تدعو

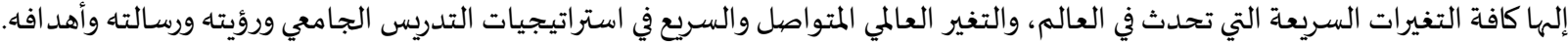

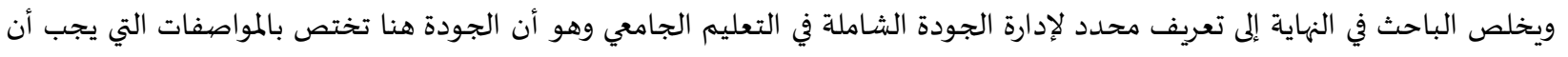

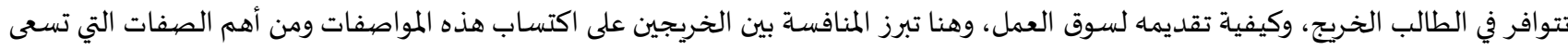

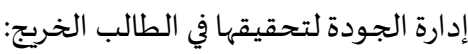

أن يكون على معرفة تامة بإجراء الأبحاث العلمية في مجال تخصصيه. يتحلى الطالب بمهارات الاتصال بالآخرين ويتقبل الرأي الآخر.

$$
\text { • أن يستطيع الطالب التفكير بنمط نقدي وإبداعي. }
$$

أن يكون قادراً على فهم واستيعاب المتغيرات العلمية والتكنولوجية المستمرة والسريعة.

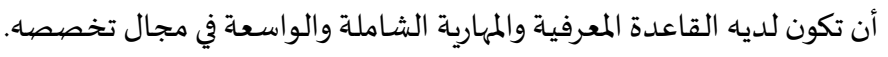
أن يكون قادراً على حل المشكلات واتخاذ القرارات بشكل علمي. أن يكون واثقاً من نفساه ومعتمد عليها.

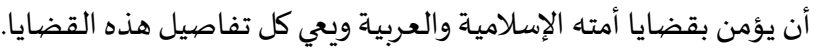
يحترم أخلاقيات المهنة. يحترم البيئة التي يعيش فيها، ويحافظ عليها. أن يكون انتماؤه لوطنه وجامعتاه محل احترام وتقدير منه.

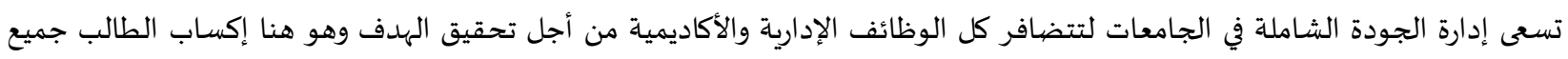

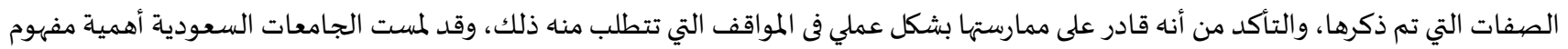
إدارة الجودة الشاملة في التعليم الجامعي وهذا يتمثل بوجود عمادة للجودة في معظم الجامعات السعودية.

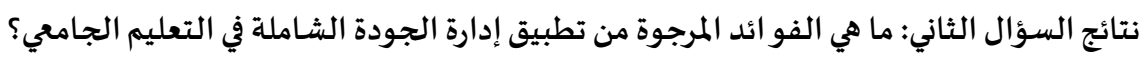

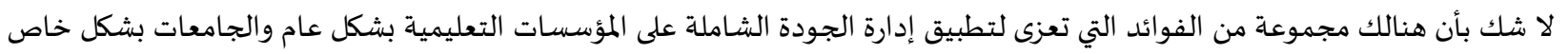

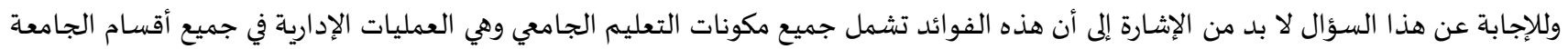

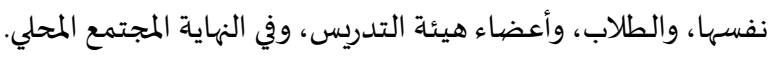

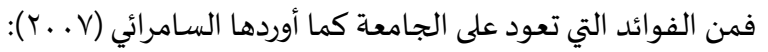

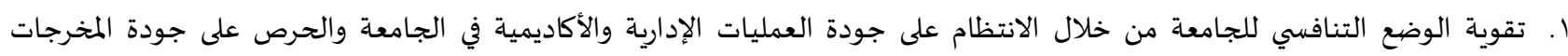
والاستمرار في تحسينها، وهذا يؤدي إلى زيادة الثقة فيها.

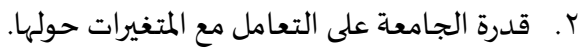
r. تحقيق إنتاجية عالية والتخلص من الإهدار من خلال تحسين نظام الإنتاج والعمليات وطرق حل المشكلات، وسبل تقويم الأداء وتحسين إدارة الوقت والتخلص من الأساليب الروتينية في إدارة الجامعة. ع. تعزيز ثقة الطلاب والمجتمع المحلي بالجامعة.

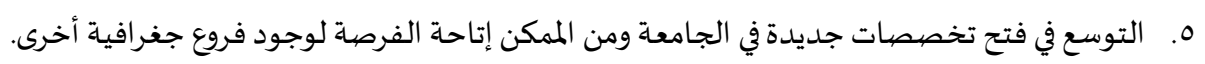
7.

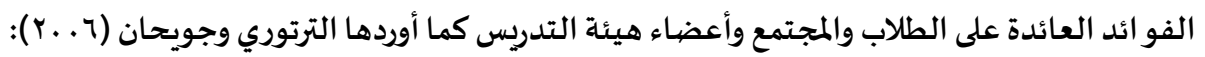

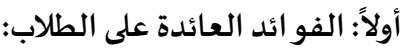
تمكن الطالب من اكتشاف المعرفة بنفسه، من خلال تقديم مهارات البحث العلمي، والقدرة على التحليل والتركيب، والتقويم، وأساليب التعلم

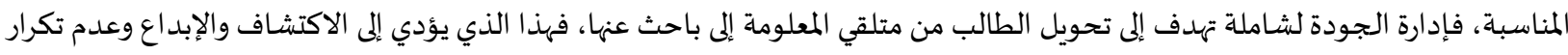
المعرفة من جيل لآخر. • تساهم في احتفاظ الطالب بالمعرفة لمدى طويل حيث أن إدارة الجودة الشاملة تدعو لاستخدام وسائل تدريسية قائمة على الفهم وليس الحفظ المائ

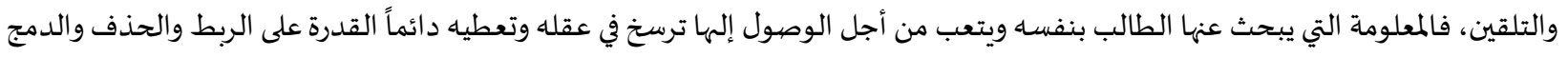
مما يجعل من المعلومة طريق لتوليد معلومات أخرى. 
تنمي المعرفة البنائية لدى الطالب؛ لأن الجودة التعليمية لا تتجاهل المعرفة والخبرات السابقة بل تقوم بالبناء عليها للتوصل إلى معرفة جديدة، فالمطلوب من الطالب أن لا يكرر ما تعلمه في مواقف تعليمية محددة بل تطبيقها في مواقف مختلفة عن الموقف التعليمي الذي تلقاها فيه. تساعد الطالب في تطبيق المعرفة الجديدة وإيصال ما يعرفه للآخرين، فإدارة الجودة في التعليم الجامعي تهدف إلى إفادة المجتمع المحلي للجامعة

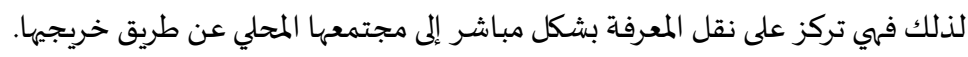
تركز على جميع الجوانب التعليمية والنفسية والمعرفية والمهارية والوجدانية لدى الطالب وتدعمها، حيث أن الطالب بالنسبة لإدارة الجودة الشاملة تركيبة بشرية متكاملة لا تهتم بالجانب المعرفي لدياه بل بكل جوانبها فالإنسان السليم لا بد من أن تكون جميع أبعاده الجسمية والنفسية والوجدانية والمهارية سليمة. تعمل على تقليل الهدر التربوي المتمثل بالرسوب والتسرب من الجامعاة، فإدارة الجودة الشاملة تقوم بتوفير بيئة تعليمية مناسبة تجعل الطالب يتمسك بالجامعة ويحبها ولا يفكر بأن يقوم بتركها. ترسخ مفاهيم المشاركة والعمل ضمن فريق، إن إدارة الجودة الشاملة في التعليم الجامعي تعتبر في الأساس ثقافة مؤسسية فلذلك تقدم مجماهوعاة من القيم الإيجابية التي تحرص على أن يؤمن بها الطالب ويمارسها بشكل فعلي في حياته الدراسية والعملية بعد التخرج. تعمل على جعل الطالب قادرا على حل مشكلاته من خلال التفكير وطرح بدائل عديدة من الحلول، ومن ثم اختيار البديل الأفضل، وهذا أيضياً

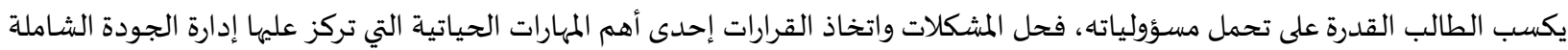
في التعليم الجامعي حيث أن تخريج طالب قادر على حل مشكلاته واتخاذ قراراته هو أولى أولوياتها. تعمل على إيجاد بيئة تعليمية مفتوحة تساعد على التعلم، يكون الطالب فيها فرد معترف فيا وتقدر حاجاته الاجتماعية والعاطفية والعقلية، دائما تقوم إدارة الجودة الشاملة بالعمل على جعل الجامعة جامعة مجتمعية مفتوحة على مجتمعها تؤثر فيه ويؤثر فيها قادرة على إيجاد حلول

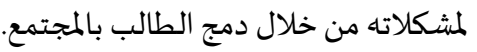

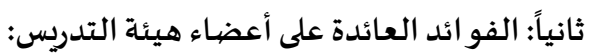

هعل الجامعة بيئة جاذبة لأعضياء هيئة التدريس المتميزين، وجعلها قادرة على الاحتفاظ بالأعضاء المتميزين الموجودين لديها. تحرص إدارة الجودة الشاملة في التعليم الجامعي على رفع كفاءة أعضاء التدريس في الجامعات من خلال الدورات التدريبية النابعة من الاحتياجات التدرببية الحقيقية. تقديم أنواع عديدة من التشجيع مثل الحوافز المادية والمعنوية والتي تهدف إلى تنمية القدرات والمهارات لدى أعضياء هيئة التدريس في التعليم الجامعي. تحرص إدارة الجودة الشـاملة على إطلاع أعضاء هيئة التدريس على ما كل هو جديد في أسـاليب وطرائق التدريس. تقدم ما هو جديد في مجال القياس وتقييم وتقويم الطلبة.

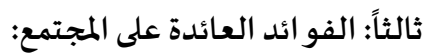
مراجعة المنتج التعليمي (الطالب)، من حيث القيمة والتأثير على المجتمع، ومدى وعي وتمكن الطالب من مجموعة المتغيرات السلوكية

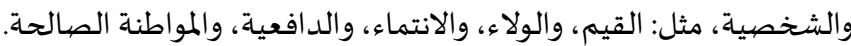
مراجعة المنتج التعليمي (التغيرات الثقافية، والاقتصادية، والتقنية، والاجتماعية) التي يحدثها التعليم الجامعي في المجتمع من خلال تنشئة الأفراد فياه، والتي يهدف من خلالها إلى تقدماهـ. اكتشاف حلقات الهدر المالي، والبشري، والزمني، وتقدير معدلاتها وتأثيرها في كفاءة التعليم الجامعي.

تحرص إدارة الجودة الشاملة في التعليم الجامعي على تخريج طاقات بشرية مؤهلة للعمل في والإنتاج، وقادرة على أن تساهم في عملية التنمية. مراعاة الاحتياجات التي يتطلهها المجتمع الذي تتواجد باء الجامعة.

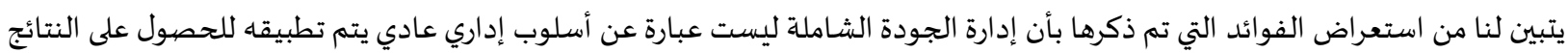
المرجوة وتحقيق الأهد اف فقط، ولكنها فلسفة إدارية تستهدف جميع مكونات المؤسسة التعليمية، ولا تترك أي عنصر من عناصرها إلا وتضعاء تحت بـان

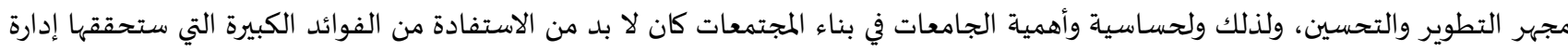
الجودة الشاملة في التعليم الجامعي. 


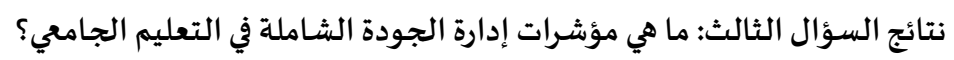

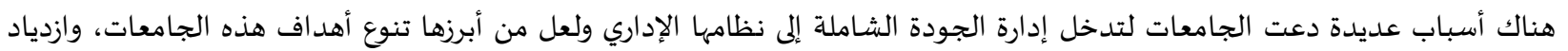

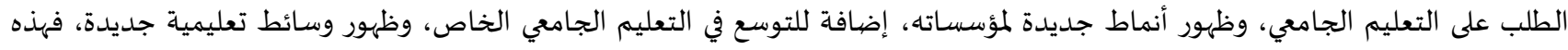

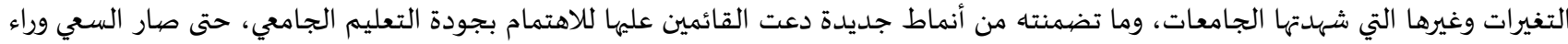

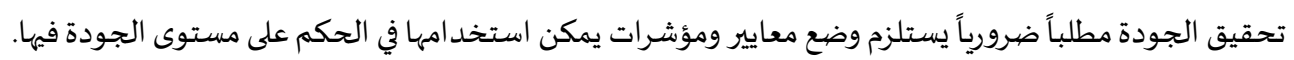

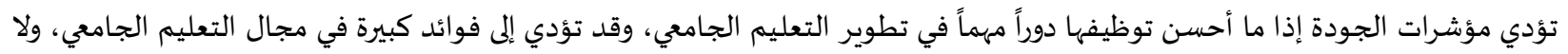

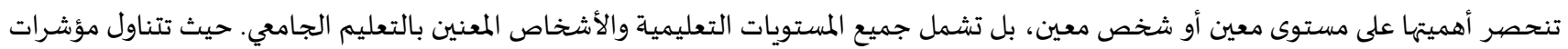

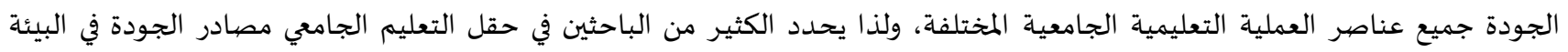

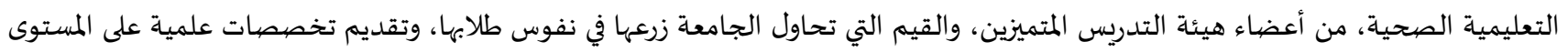
المطلوب، وتعاون كل من الجامعة والمجتمع المحلي.

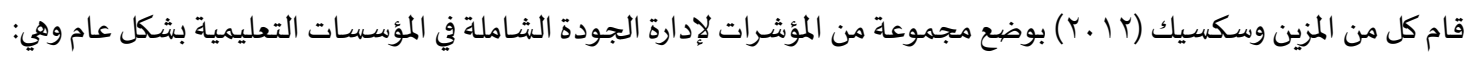

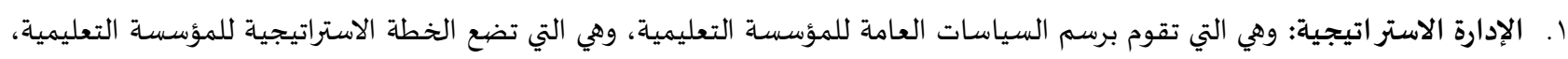

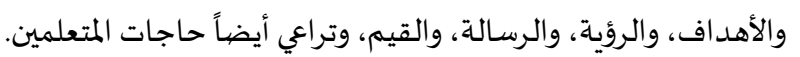

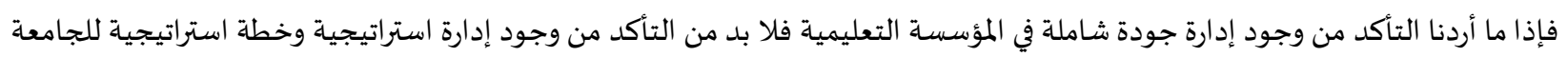

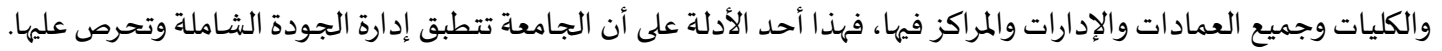

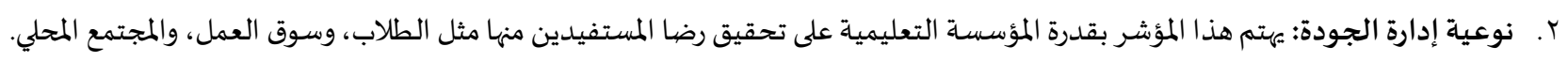

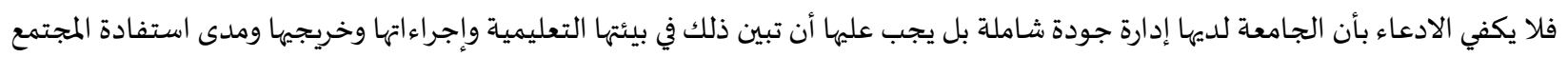
المحلي منها.

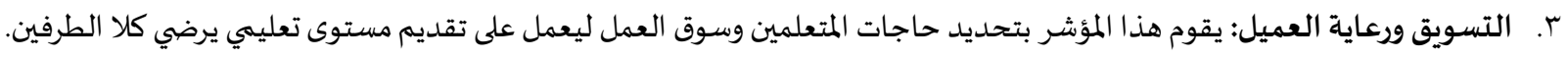

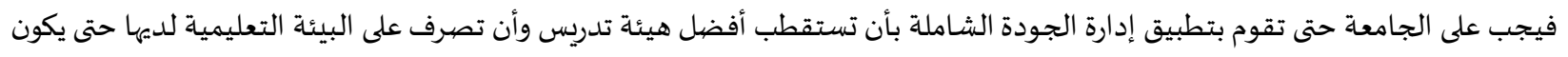

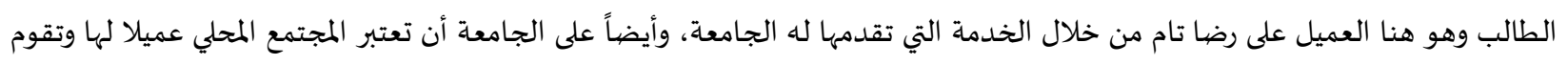

بدراسة احتياجاته وتلبيتها. ع. تطوير الموارد البشرية: ههتم هذا المؤشر بفعالية الموظفين في المؤسسة التعليمية سواء كانوا إداريين أو أكاديميين ليتأكد من أهمم جميعاً يقومون بأعمالهم بالطريقة الصحيحة.

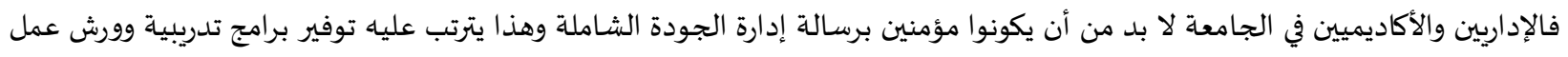

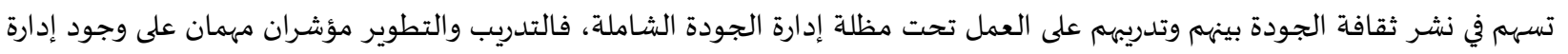
الجودة الشاملة في الجامعة. 0. تكافؤ الفرص: وهذا مؤشر وقيمة في نفس الوقت بحيث يشعر جميع المتعلمين بأنهم جميعاً متساوون في الحصول على خدمة تعليمية ممتازة،

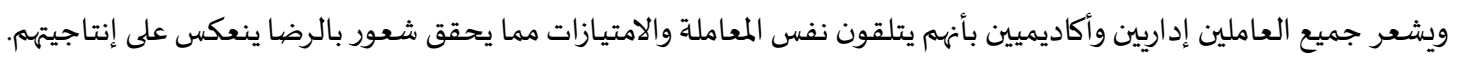

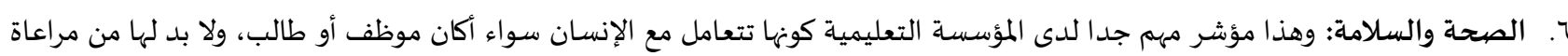
جميع ظروف الصحة والسلامة في بيئتها.

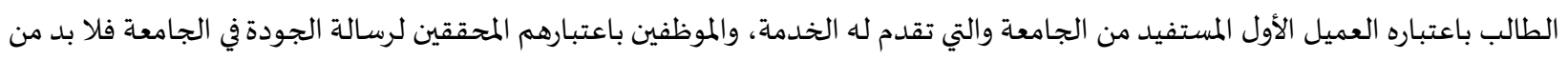
الحرص على توفير بيئة دراسة وعمل تتسم بالسلامة. V. الاتصال والإدارة: يطلب هذا المؤشر من المؤسسة التعليمية بأن يكون لديها نظام اتصال فعال يشال يشارك فيها جميع الأطراف التي تربطها علاقة بالجامعة للحصول على علاقة ديمقراطية ترضي جميع الأطراف.

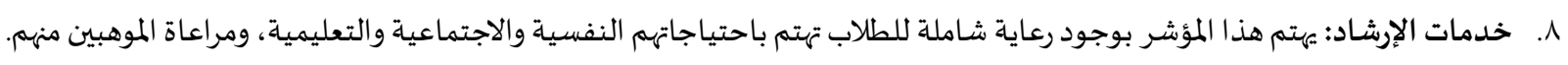

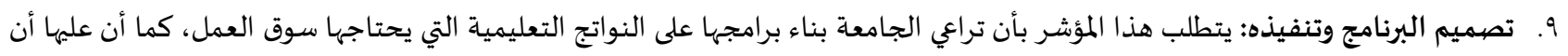

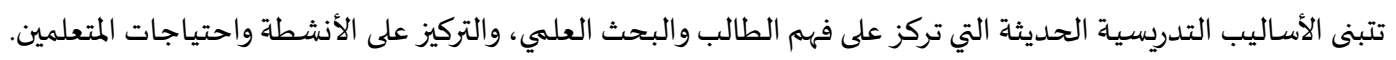

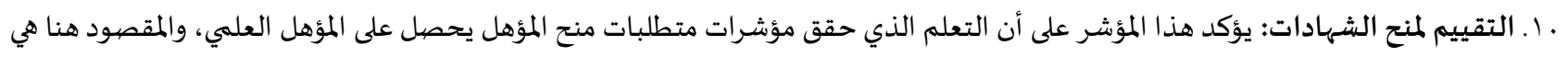

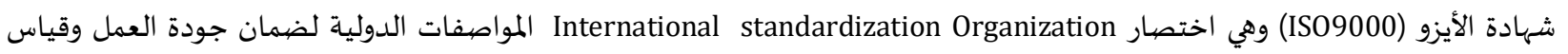

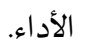


ولقد صنفت منظمة ألبرت في التربية مؤشرات الجودة التعليمية وأوردتها في مقالة خاصة بالعناصر التالية:

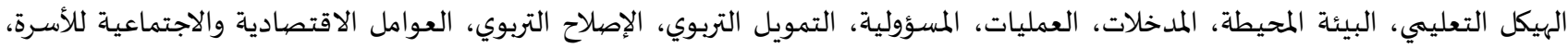

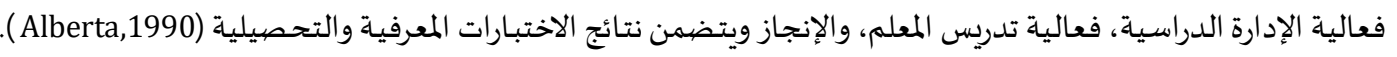

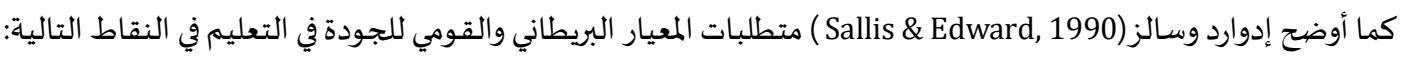

$$
\begin{aligned}
& \text { التزام الإدارة في الجودة. } \\
& \text { سياسـة القبول والاختيار. } \\
& \text { تسجيل مدى تقدم الطالب. } \\
& \text { تطوير المنهاج والاستراتيجيات التعليمية التدريسية. } \\
& \text { اتساق أساليب التقويم. } \\
& \text { تحديد الإنجازات المتدنية والعمل على تصحيحها والتعامل مع نواحي الضعف. } \\
& \text { تحديد الاحتياجات التدريبية وتطويرها. } \\
& \text { تقويم فعالية التدريب. } \\
& \text { المراقبة والتقويم. }
\end{aligned}
$$

وظهرت بحوث بيركي وسميث (1990, Smith \& Purkey) والتي أدت إلى تغيير قائمة مواصفات المؤسسة التعليمية الفاعلة، وكشفت هذه الدراسـات النقاب على أن هذه المواصفات ترتبط بتحصيل عالٍ للطلبة، وفي مجال التعليم وضعت جامعاة شمال فلوريدا بالولايات المتحدة الأمريكية تسعة مؤشرات للجودة في المؤسسات التعليمية. (Valeria,1998) وكانت على النحو التالي:

$$
\text { التقدم التربوي. }
$$

وقام ستانلي جوردون (Stanley, 1995) بدراسـة تتناول مؤشرات الجـودة والأداء في الجامعات الأسترالية حيث كشف عن العلاقة بين الأداء الكمي

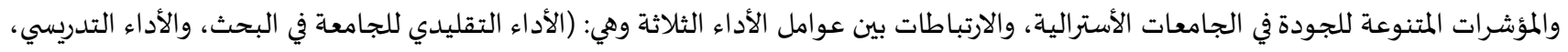

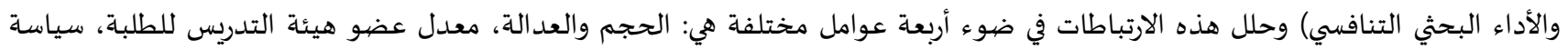

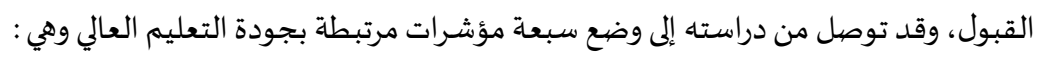

$$
\begin{aligned}
& \text { مستوى الخريج الجامعي. } \\
& \text { إنتاجية أعضاء هيئة التدريس في نشر بحوثهم. } \\
& \text { حجم المؤسسة التعليمية . } \\
& \text {.الظروف المإلسة والإنفاق (تكلفة كل طالب في العملية التعليمية). }
\end{aligned}
$$

عدد الطلبة في المؤسسة التعليمية (معدلات أعضاء هيئة التدريس بالنسبة للطلبة).

نلاحظ مما سبق ذكره عن مؤشرات إدارة الجودة الشاملة في التعليم الجامعي، بوجود خصوصية لتلك المؤشرات نابعة من خصوصية التهية الجامعة كمؤسسة تعليمية منتجها النهائي هو الإنسان وهنا يمكن للباحث أن يجمع مؤشرات إدرات إدارة الجودة الشودة الشاملة بناء على ما سبق فيما يلي: 
مؤشر الطلاب:

ينبثق عن هذا المؤشر عدد من المؤشرات الفرعية وهي:

مؤشر اختيار الطلاب للالتحاق بالجامعة حيث من المهم أن تقوم الجامعة باختيار طلبتها عن طريق عدد من الاختبارات القبلية للقبول حيث

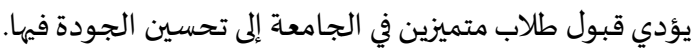

مؤشر التدريس الذي سوف يتلقاه هؤلاء الطلاب، على الجامعة الحرص على تلقي الطلبة لتعليم عالي الجودة من حيث استخدام أفضل وأحدث

الأساليب التدريسية التي تعتمد على البحث والتفكير.

مؤشر الرعاية الشاملة التي يحاط بها الطالب من مصادر تعليمية مثل المختبرات، والمكتبات، وأيضياً الدعم والإرشاد الأكاديمي والنفسي. مؤشر نسبة أعضاء هيئة التدريس لعدد الطلاب في الجامعة حيث تتوقف جودة التعليم على وجود أعضاء هيئة تدريس قادرين على القيام

بمهامهم وهذا لن يحصل إلا بوجود عدد كافٍ منهم بأقل تكلفة ويحقق أعلى كفاية.

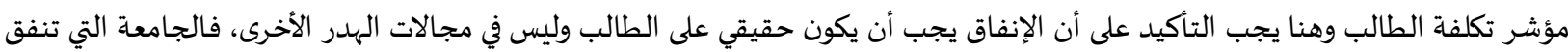
أكثر على طلبتها تحقق معايير أكثر من الجودة. مؤشر الدافعية لدى الطلاب فلا وجود لجودة في التعليم الجامعي بدون وجود دافعية حقيقة لدى طلابه، وهنا على الجامعة خلق دافعية لدى طلبتها من خلال التوعية بأهمية التعليم الجامعي، وتوفير حوافز تدفعهاه للتعلم. مؤشر الحرص على تقديم طالب جامعي يتمتع بالمهارات والتخصصيات التي يحتاجها سوق العمل في البيئة الخارجية للجامعة وهذا يُعد من أهم مؤشرات الجودة في الجامعات. مؤشر مستوى الخريج الجامعي فكلما كان مستوى الخريج عالياً في مجال تخصصها وفي مهارات الحياة التي يحتاجها كانت جودة التعليم الجامعي عالية. مؤشر أعضياء هيئة التدريس: لا يمكن فصل جودة التعليم الجامعي عن فاعلية وكفاءة أعضياء هيئة التدريس فياء، فعدد أعضياء هيئة التدريس يجب أن يكون مناسباً لعدد

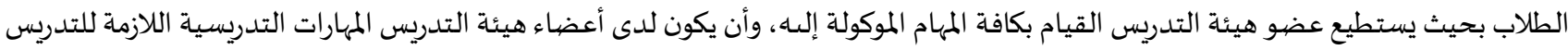

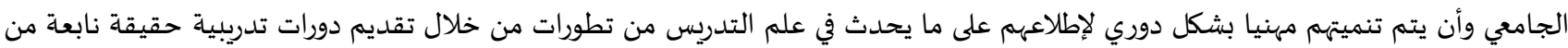

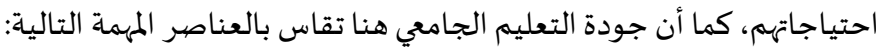
الإنتاج العلمي لعضو هيئة التدريس من خلال نشره للأبحاث العلمية. كتابة المقالات العلمية. المشاركة في المؤتمرات ذات العلاقة بتخصصيه. الاشتراك بالجمعيات العلمية داخل وخارج بلادهم.

مؤشر المناهج الدراسية:

إن الخطط والبرامج التدريسية التي تقدمها الجامعات لها دور كبير في تقديم مؤشرات جودة عالية، حيث أن المناهج التي تصممم لمحاكاة عقول

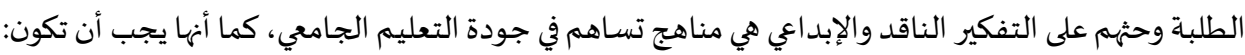
مرتبطة بثقافة الطالب ومعتقداته ومجتمعاه ومنفتحة على الرأي والرأي الآخر.

أن تكون قادرة على إحداث تغيير مرغوب في سلوك الطلاب وثقفاتهم وتنميتهم فكرياً. عليها أن تراعي الفروق الفردية بين الطلاب، حيث إن المناهج الدراسية هي الطريق نحو تحقيق أهداف التعليم الجامعي. مؤشر الإدارة:

يقع على الإدارة الجامعية القسم الأكبر من تحقيق الجودة في التعليم الجامعي فهي المسؤولة عن وضع السياسات العامة للتعليم الجامعي والخطط العريضة فإن لم تتبنى الإدارة الجامعية مدخل الجودة الشاملة في إدارها فسيكون من الصعب تحقيق الجودة فهها، فلذلك علهها أن تلتزم بالجودة ومعاييرها وتحقيق مؤشراتها من خلال: توفير علاقات إنسانية طيبة مع جميع الأطراف المشتركة في التعليم الجامعي. فتح قنوات اتصال مختلفة فيما بينهم. القيام بتدريب الإداريين في الجامعة بالشكل الذي يتواءم مع إدارة الجودة الشـاملة. 
مؤشر علاقة الجامعة بالمجتمع المحلي:

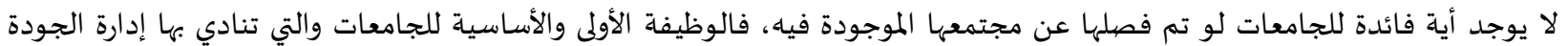
الشاملة في التعليم الجامعي هي تخريج طلبة قادرين على:

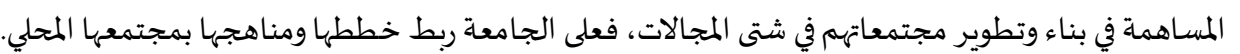

تكريس البحث العلمي لديها لعلاج وحل المشكلات التي يعاني منها المجتمع المحيط بها.

تدرس احتياجات سوق العمل في المجتمع ورسم برامجها الأكاديمية بناء على ذلك حتى لا تسهم في ازدياد صفوف العاطلين عن العمل.

وجود شراكة حقيقية بين مؤسسات المجتمع المحلي الحكومية والخاصة في دعم التعليم الجامعي وتقديم المساعد ات العينية والمادية للجامعاة.

نتائج السؤال الر ابع: ما العوامل المؤثرة في إدارة الجودة الشاملة ومدحاورها في التعليم الجامعي؟

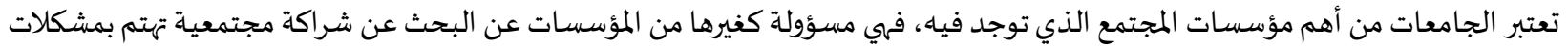

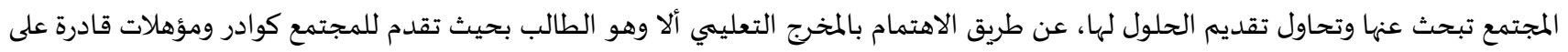
تطوير المجتمع وخدمتاه، وكون الجامعات هي إحدى أهم المؤسسات الاجتماعية فهي تتأثر بالعديد من العوامل التي تؤثر على المجتمع نفساه ومن هذه

العوامل:

• • العامل الاقتصادي: يعتبر العامل الاقتصادي من أهم العوامل المؤثرة في أي نظام تعليمي عام أو جامعي سواء أكان هذا التاثير إيجابياً أو سلبياً، الماتئ.

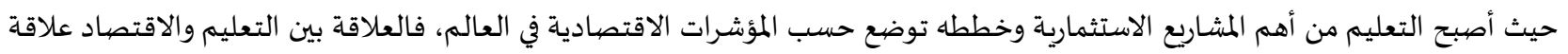

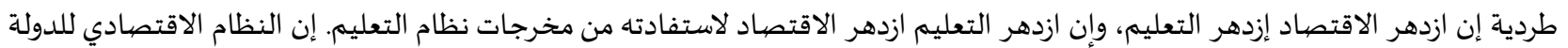

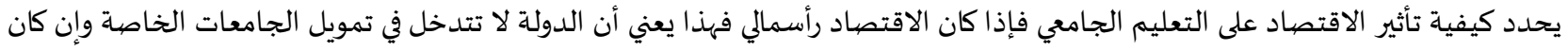

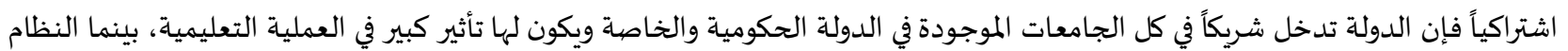
الاقتصادي الإسلامي إذا ما استخدم بالفهه والشكل الصحيح فإنه يؤمن بحرية التفكير والإبداع لدى الفرد، وبالتالي فإن النظرية الاقتصادياة

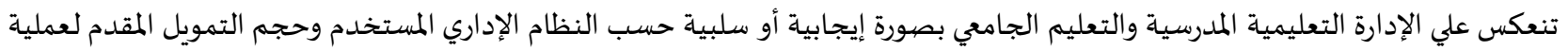

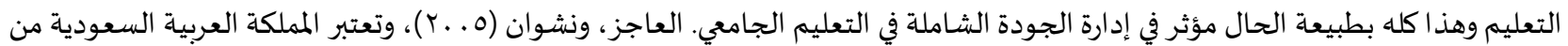

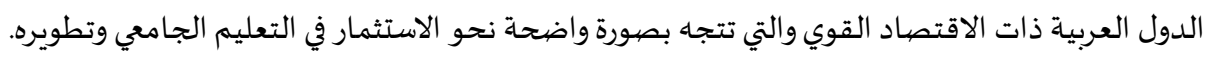
العامل السياسي: يؤثر العامل السياسي بشكل كبير في تشكيل النظام التعليمي والتخطيط له، ذلك أن النظام التعليمي بأنواعه ومراحله يحدد وفق العامل السياسي، فالطبيعة السياسية هي التي تحدد السياسة التعليمية للجامعات وتتدخل بوضع البرامج التعليمية وخططها، وتتسم المملكة العربية السعودية بنظام سياسي مستقر لذلك نجد بأن الاهتمام بالجامعات السعودية وتطويرها يستولي على الاهتمام الأكبر لدى الحكومة

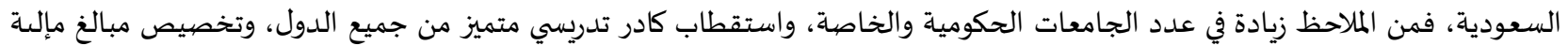
كبيرة للبحث العملي في الجامعات. العامل الاجتماعي: إن طبيعة تكوين الدولة الاجتماعية من حيث الاستقرار المجتمعي يؤثر إيجابياً وبشكل كبير على التعليم الجامعي في هذه الدولة، حيث أن التمسك بالدين وبالعادات والتقإلـد ووجود تكافل اجتماعي بين أفراد المجتمع، وسيادة مفاهيم الاحترام والتعاون والعدل واحترام قيمة

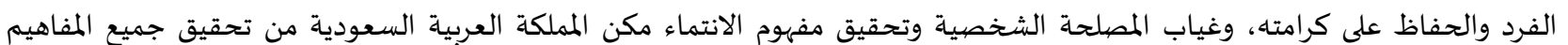
الاجتماعية التي بدورها حققت استقراراً. يوجد الكثير من العوامل المؤثرة في إدارة الجودة الشـاملة ومحاورها في التعليم الجامعي، إلا أن العوامل الثماثلاثة أعلاه برأي الباحث من أهم العوامل المؤثرة في إدارة الجودة الشاملة وهناك العديد من العوامل المؤثرة والتي يجب احتوائها في الحاضر حتى تتمكن الجامعات من مواجهتها مثل وسائل

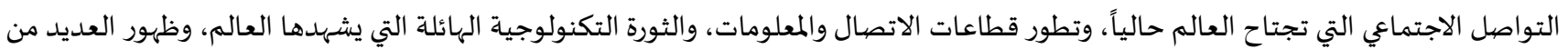
المفاهيم الحديثة بين الشباب.

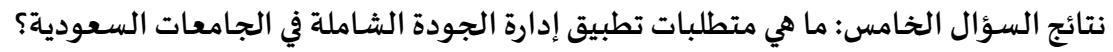

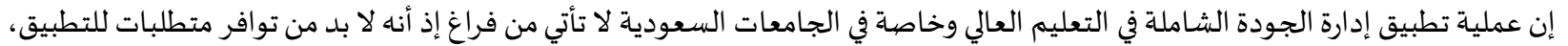
وهذه المتطلبات ضرورية حتى تستقيم إدارة الجودة في الجامعات على طريقها الصحيح وتحقق الهدف المرجو منها، وتهدف هذه المتطلبات بداية إلى تقبل

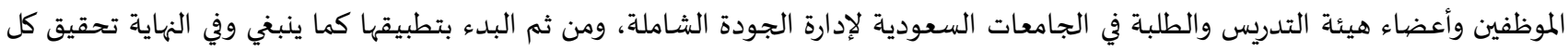

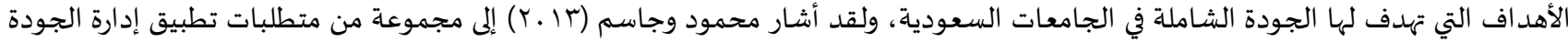
الشاملة في الجامعات كما يلي: 
التركيز على العميل: يجب على الجامعات السعودية التي تريد تطبيق إدراة الجودة الشاملة في خططها أن تقوم بتحليل العملاء المستفيدين من

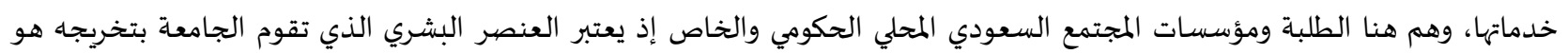

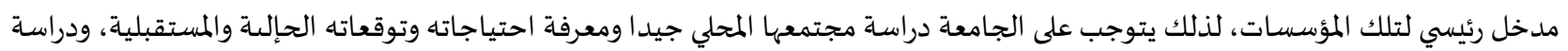

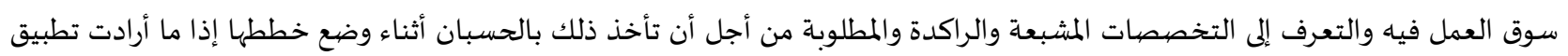

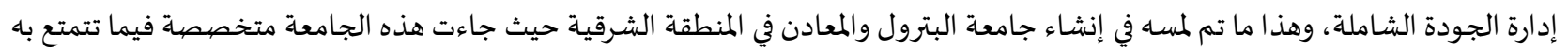

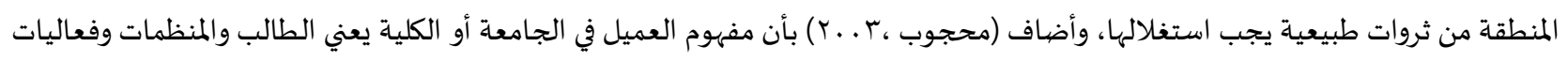

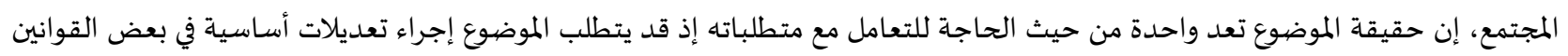

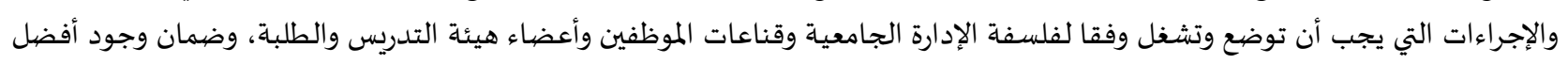

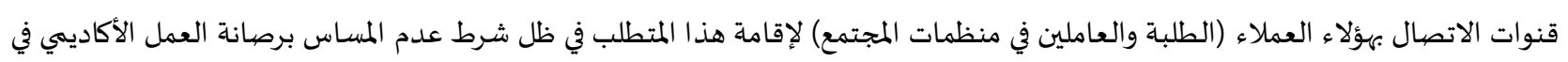

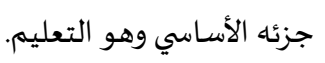

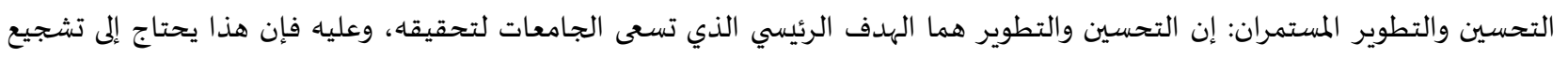

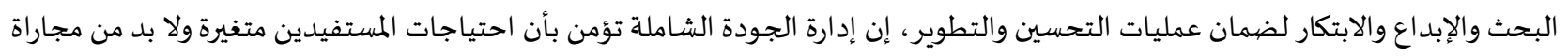

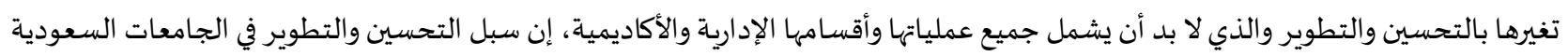

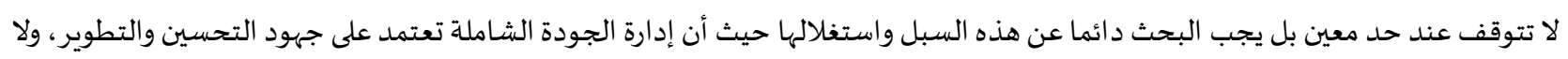

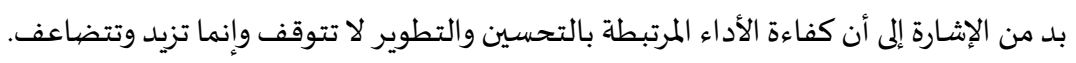

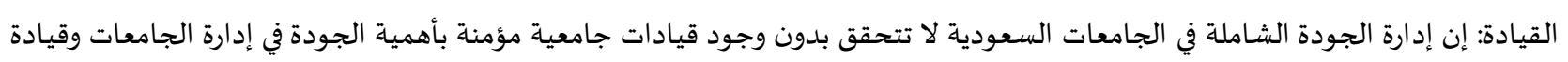

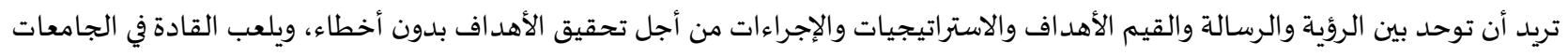

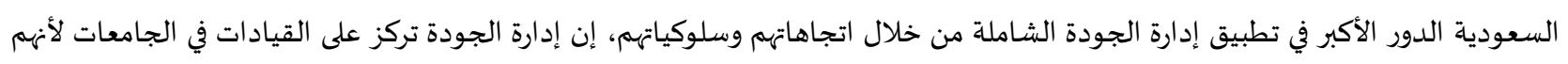

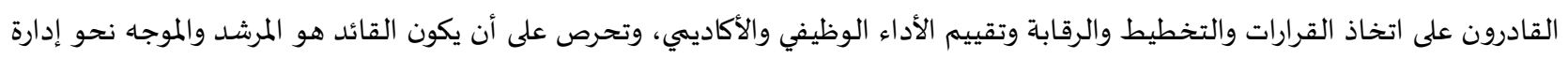

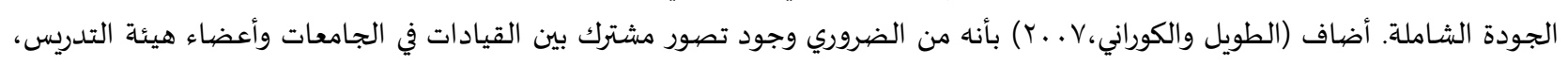

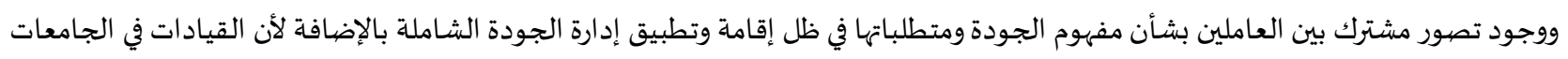

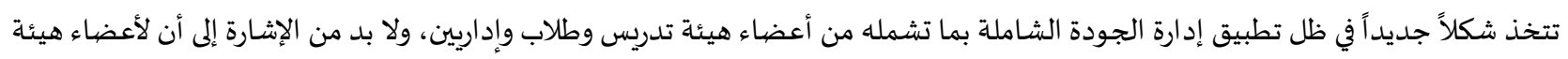

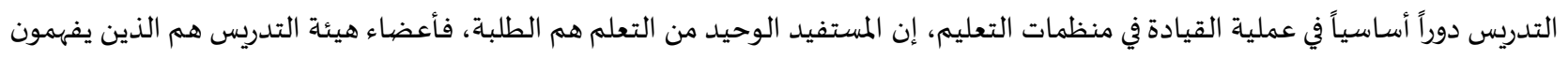

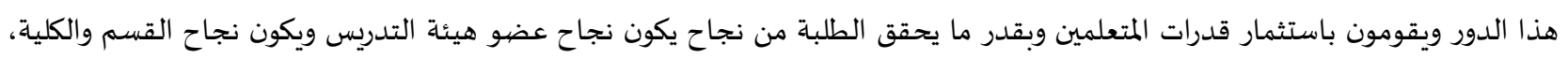
ويكون نجاح الجامعات، وكل ذلك ينعكس على تطور المجتمع بالتأكيد.

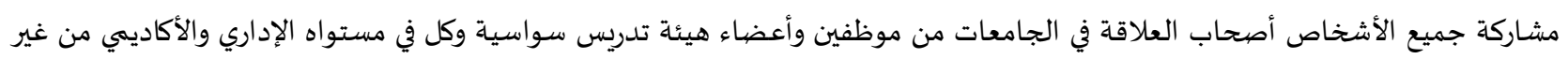

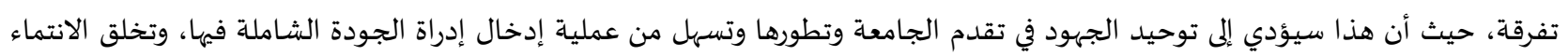

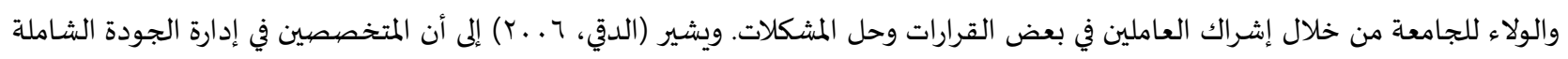

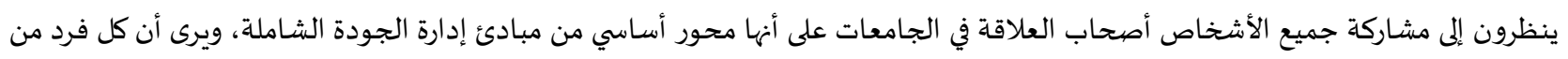

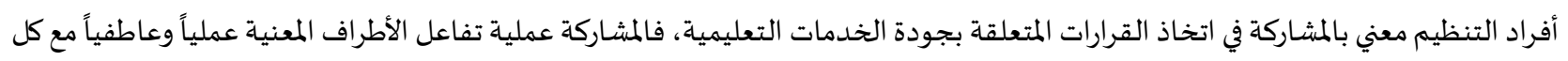

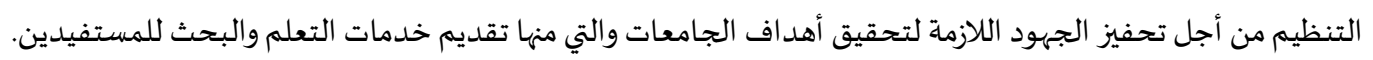

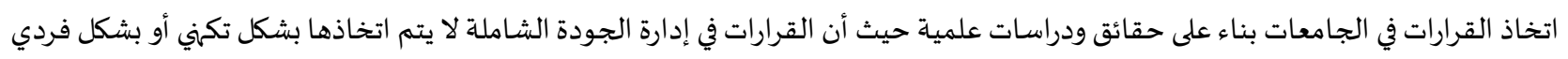

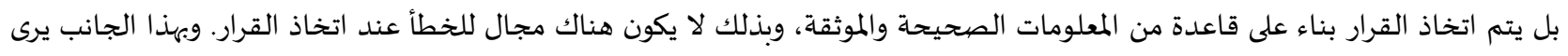

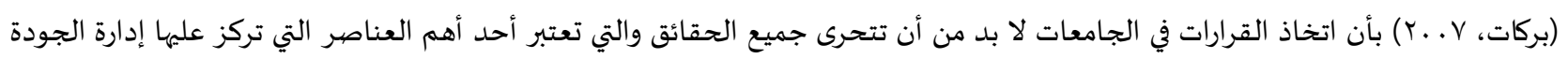

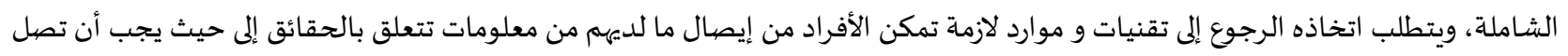

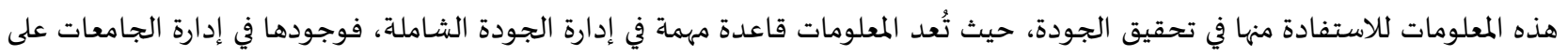

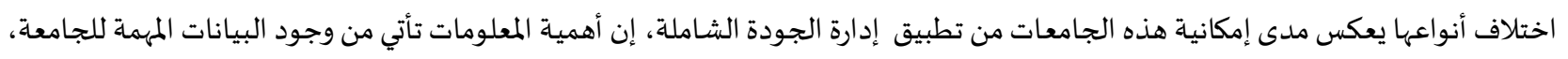

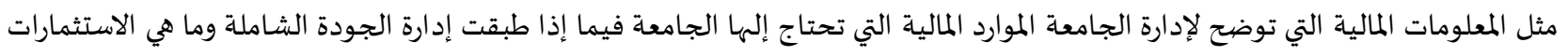

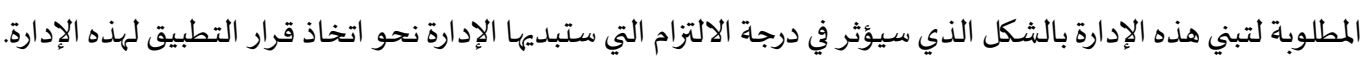

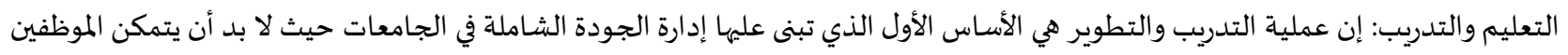

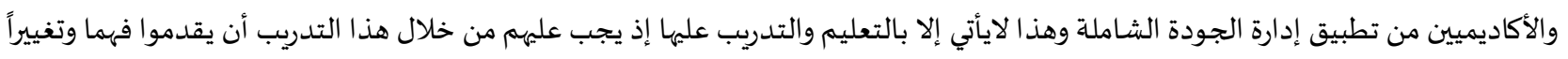




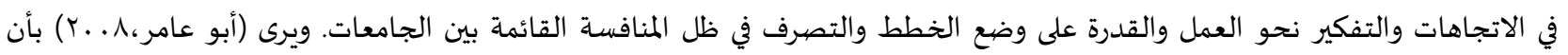

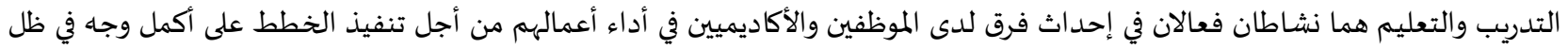

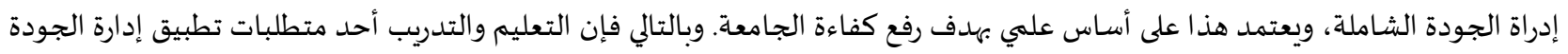

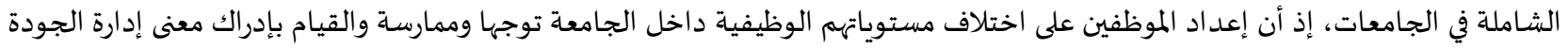

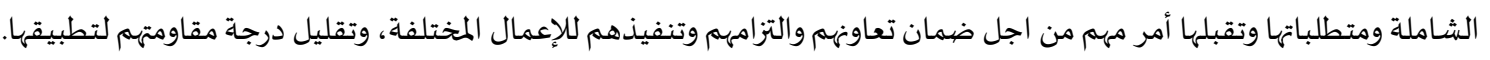

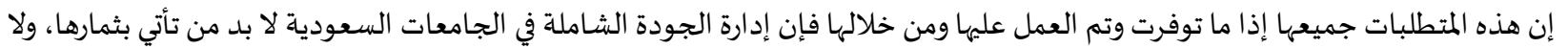

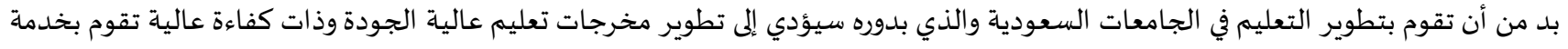
المجتمع الموجودة فيه وتهض بسوق العمل وتحقيق نهضة مجتمعية سعودية.

التوصيات:

استناداً إلى نتائج الدراسة توصل الباحث إلى التوصيات التالية:

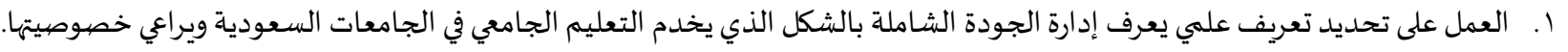

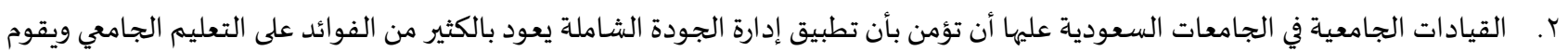

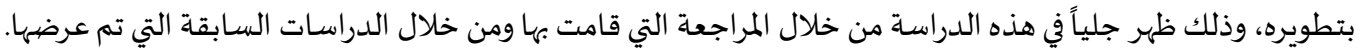

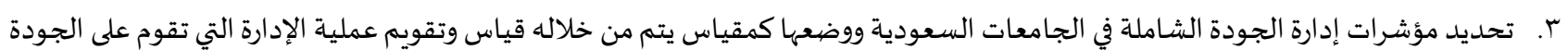
الشاملة. ع. يجب على الجامعات السعودية الأخذ بعين الاعتبار جميع العوامل الداخلية والخارجية التي تؤثر على إدارة الجودة الشاملة في الجامعات، وتتكيف معها وتطوعها لصالحها في عملية التطبيق. 0. تركيز القيادات الجامعية في الجامعات السعودية على توفير المتطلبات اللازمة لإدارة الجودة الشاملة لديها إذ لا يمكن الوصهول إلى جودة شاملة من غير توفير هذه المتطلبات والعمل عليها.

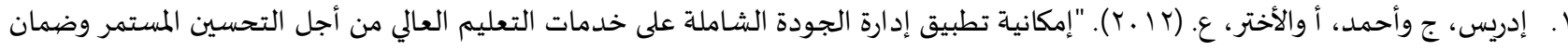

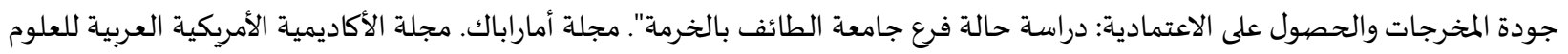

والتكنولوجيا: V V) V (Y).

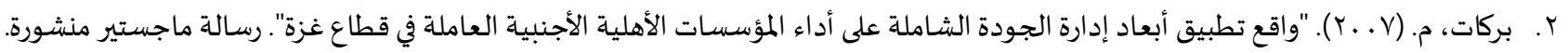
كلية التجارة. الجامعة الإسلامية. غزة. فلسطين. r. الترتوري، م وجويحان، أ. (7 . .ب). إدارة الجودة الشاملة في مؤسسات التعليم العالي والمكتبات ومراكز المعلومات. عمان: دار المسيرة للطباعة

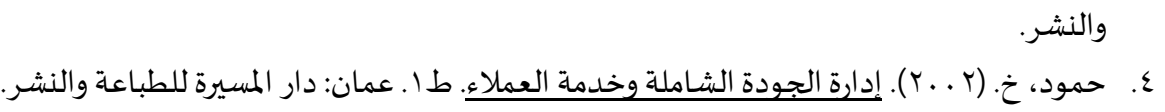

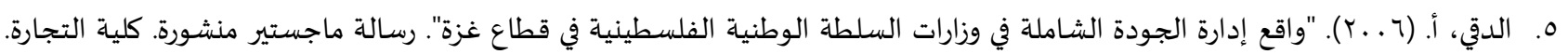

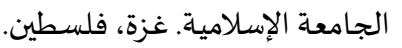

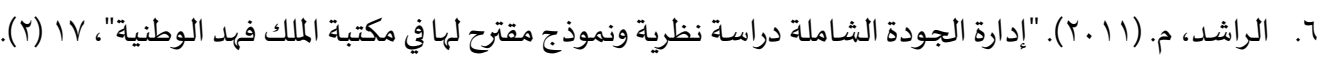

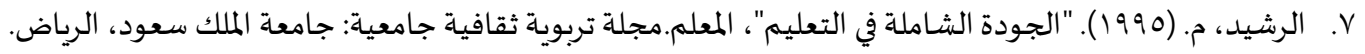

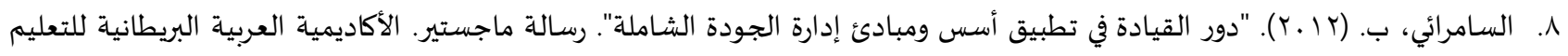

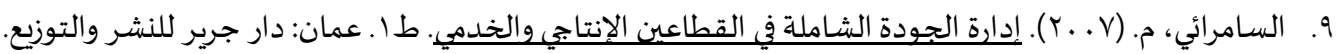

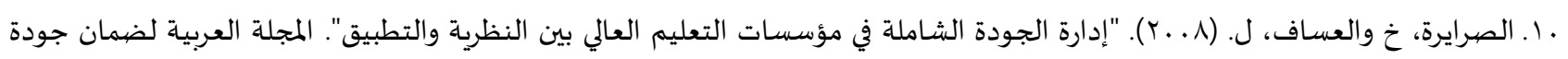

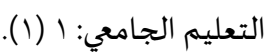

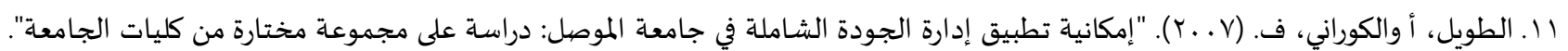

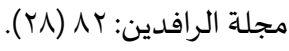


r ا. العاجز، ف ونشوان، ج. (0. . ب). "تطوير التعليم الجامعي لتنمية المجتمع الفلسطيني في ضوء إدارة الجودة الشاملة". الجودة في التعليم العالي: 1

r ا. أبو عامر، آ. (1. . ب). "واقع الجودة الإدارية في الجامعات الفلسطينية من وجهة نظر الإداريين وسبل تطويره". رسالة ماجستير منشورة. كلية التربية. الجامعة الإسلامية. غزة. فلسطين.

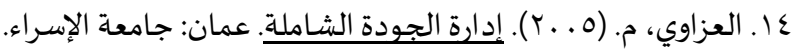

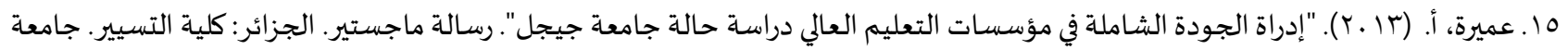

7 ا. قادة، ي. (r ا ـ Y) "واقع تطبيق إدارة الجودة الشـاملة في مؤسسات التعليم الجزائرية: دراسة تطبيقية على متوسطات ولاية سعيدة". رسالة ماجستير. الجزائر: كلية العلوم الاقتصادية. جامعة أبي بكر بلقايد.

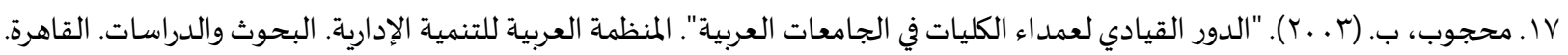

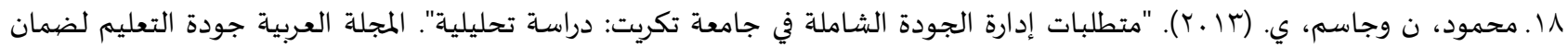

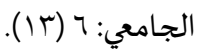

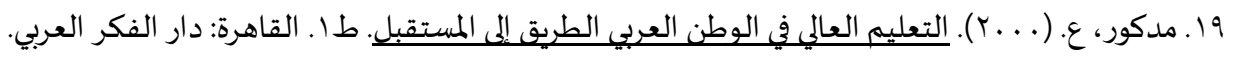

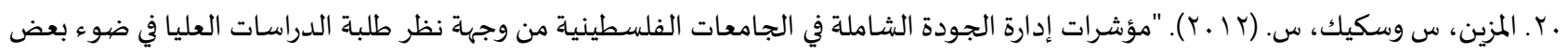

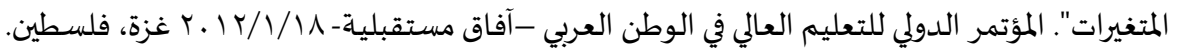

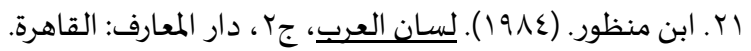

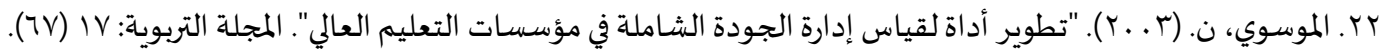

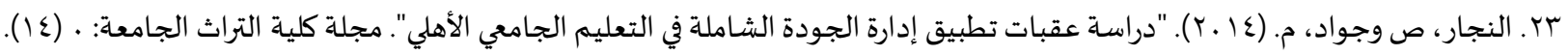

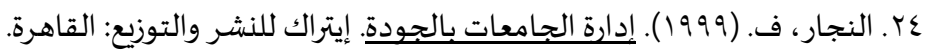

ثانياً: المراجع الأجنبية:

[1] Albent, E, (1990). Educational Quality Indicators. Annotated Biblio-graphy, 2nd ed. Canada.

[2] Barton \& Marson, D. (1991). Service Quality. An introduction Province of British Columbia Publication.

[3] Deming, E. (1986). “Out of the Crisis”. Cambridge: MIT, Center for Advanced Engineering Study.

[4] Edward, S. (1991). Total Quality Management, OP. CIT.

[5] Rhodes, L. (1992). “On Road to Quality”. Educational Leadership. 49 (6).

[6] Stanley, G. (1995). "Performance Indicators and Quality Review in Australian University", in Higher Education Research and Development. 14(2):245-253, https://doi.org/10.1080/0729436950140207. 


$$
\text { المجلة الدولية للدراسات التربوية والنفسية }
$$

International Journal of Educational \& Psychological Studies (EPS)

Journal Homepage: https://www.refaad.com/views/EPSR/Home.aspx

www.refaad.com

ISSN: 2520-4149 (Online) 2520-4130 (Print)

\title{
Developing education in Saudi universities through applying the requirements of TQM (Total Quality Management) in university education
}

Orwah Mohammed Hamdan

Assistant professor, Taibah university, Deanship of Academic services, KSA orwahlor2000@yahoo.com

\begin{abstract}
:
The study aimed at revealing how to develop education in Saudi universities through applying the requirements of TQM in university education.

In order to achieve the objective of the study, the researcher, through the descriptive analytical study method, analyzed the literature on administrative thought in TQM, and collecting information, analysis and interpretation to benefit from the study.

After conducting an analysis of the literature on the subject of the study, the results indicated that a specific definition of TQM is necessary in university education and that there are many benefits to universities if the requirements of TQM are applied correctly in university education. TQM indicators in university education. The results revealed the most important factors affecting TQM. Finally, the requirements for the application of TQM in Saudi university education were determined.

In the light of the results, the researcher recommended working on defining a scientific definition known as TQM in Saudi universities. The university leaders should believe that the application of TQM has a lot of benefits to the university education and is developing it and identifying TQM indicators in Saudi universities. Taking into account all the internal and external factors affecting TQM in universities, the focus of university leaders in Saudi universities on providing the necessary requirements for TQM.
\end{abstract}

Keywords: Total Quality Management; Development of University Education; Saudi Arabia.

\section{References:}

[1] Al'ajz, F Wnshwan, J. (2005). "Ttwyr Alt'lym Aljam'y Ltnmyt Almjtm' Alflstyny Fy Dw' Edart Aljwdh Alshamlh". Aljwdh Fy Alt'lym Al'aly: 1 (2).

[2] Abw 'amr, A. (2008). "Waq' Aljwdh Aledaryh Fy Aljam'at Alflstynyh Mn Wjht Nzr Aledaryyn Wsbl Ttwyrh". Rsalt Majstyr Mnshwrh. Klyt Altrbyh. Aljam'h Aleslamyh. Ghzh. Flstyn.

[3] 'myrh, A. (2013). "Edrat Aljwdh Alshamlh Fy M'ssat Alt'lym Al'aly Drash Halh Jam't Jyjl". Rsalt Majstyr. Aljza'r: Klyt Altsyyr. Jam't Qsnzynh.

[4] Al'zawy, M. (2005). Edart Aljwdh Alshamlh. 'man: Jam't Alesra'.

[5] Albent, E, (1990). Educational Quality Indicators. Annotated Biblio-graphy, 2nd ed. Canada.

[6] Barton \& Marson, D. (1991). Service Quality. An introduction Province of British Columbia Publication.

[7] Brkat, M. (2007). "Waq' Ttbyq Ab'ad Edart Aljwdh Alshamlh 'la Ada' Alm'ssat Alahlyh Alajnbyh Al'amlh Fy Qta' Ghzh". Rsalt Majstyr Mnshwrh. Klyt Altjarh. Aljam'h Aleslamyh. Ghzh. Flstyn.

[8] Deming, E. (1986). "Out of the Crisis". Cambridge: MIT, Center for Advanced Engineering Study.

[9] Aldqy, A. (2006). "Waq' Edart Aljwdh Alshamlh Fy Wzarat Alslth Alwtnyh Alflstynyh Fy Qta' Ghzh". Rsalt Majstyr Mnshwrh. Klyt Altjarh. Aljam'h Aleslamyh. Ghzh, Flstyn.

[10] Edrys, J Wahmd, A Walakhtr, '. (2012). "Emkanyt Ttbyq Edart Aljwdh Alshamlh 'tla Khdmat Alt'tlym Al'aly Mn Ajl Althsyn Almstmr Wdman Jwdt Almkhrjat Walhswl 'la Ala'tmadyh: Drast Halt Fr' Jam't Alta'f Balkhrmh". Mjlt Amarabak. Mjlt Alakadymyh Alamrykyh Al'rbyh Ll'lwm Waltknwlwjya: 7 (3). 
[11] Edward, S. (1991). Total Quality Management, OP. CIT.

[12] Hmwd, Kh. (2002). Edart Aljwdh Alshamlh Wkhdmh Al'mla'. T1. 'man: Dar Almsyrh Lltba'h Walnshr.

[13] Mdkwr, '. (2000). Alt'lym Al'aly Fy Alwtn Al'rby Altryq Ela Almstqbl. T1. Alqahrh: Dar Alfkr Al'rby.

[14] Mhjwb, B. (2003). "Aldwr Alqyady L'emda' Alklyat Fy Aljam'eat Al'erbyh". Almnzmh Al'erbyh Lltnmyh Aledaryh. Albhwth Waldrasat. Alqahrh.

[15] Mhmwd, N Wjasm, Y. (2013). "Mttlbat Edart Aljwdh Alshamlh Fy Jam't Tkryt: Drash Thlylyh". Almjlh Al'rbyh Jwdt Alt'lym Ldman Aljam'y: 6 (13).

[16] Abn Mnzwr. (1984). Lsan Al'rb, J2, Dar Alm'arf: Alqahrh.

[17] Almwswy, N. (2003). "Ttwyr Adah Lqyas Edarh Aljwdh Alshamlh Fy M'ssat Alt'lym Al'aly". Almjlh Altrbwyh: 17 (67).

[18] Almzyn, S Wskyk, S. (2012). "M'shrat Edart Aljwdh Alshamlh Fy Aljam'at Alflstynyh Mn Wjht Nzr Tlbt Aldrasat Al'lya Fy Dw' B'd Almtghyrat". Alm'tmr Aldwly Llt'lym Al'aly Fy Alwtn Al'rby -Afaq Mstqblyh- 18/1/2012 Ghzh, Flstyn.

[19] Alnjar, S Wjwad, M. (2014). "Drash 'qbat Ttbyq Edart Aljwdh Alshamlh Fy Alt'lym Aljam'y Alahly". Mjlt Klyt Altrath Aljam'h: 0 (14).

[20] Alnjar, F. (1999). Edart Aljam'at Baljwdh. Eytrak Llnshr Waltwzy': Alqahrh.

[21] Qadh, Y. (2012) "Waq' Ttbyq Edart Aljwdh Alshamlh Fy M'ssat Alt'lym Aljza'ryh: Drash Ttbyqyh 'la Mtwstat Wlayh S'ydh". Rsalt Majstyr. Aljza'r: Klyh Al'lwm Alaqtsadyh. Jam'eh Aby Bkr Blqayd.

[22] Rhodes, L. (1992). “On Road to Quality”. Educational Leadership. 49 (6).

[23] Alrshyd, M. (1995). "Aljwdh Alshamlh Fy Alt'lym", Alm'lm.Mjlt Trbwyh Thqafyh Jam'yh: Jam't Almlk S'wd, Alryad.

[24] Alrashd, M. (2011). "Edart Aljwdh Alshamlh Drash Nzryh Wnmwdj Mqtrh Lha Fy Mktbh Almlk Fhd Alwtnyh", 17 (2).

[25] Alsamra'y, B. (2012). "Dwr Alqyadh Fy Ttbyq Ass Wmbad' Edart Aljwdh Alshamlh". Rsalt Majstyr. Alakadymyh Al'rbyh Albrytanyh Llt'lym Al'aly.

[26] Alsamra'y, M. (2007). Edart Aljwdh Alshamlh Fy Alqta'yn Alentajy Walkhdmy. T1. 'man: Dar Jryr Llnshr Waltwzy'.

[27] Alsrayrh, Kh Wal'saf, L. (2008). "dart Aljwdh Alshamlh Fy M'ssat Alt'lym Al'aly Byn Alnzryh Walttbyq". Almjlh Al'rbyh Ldman Jwdh Alt'lym Aljam'y: 1 (1).

[28] Stanley, G. (1995). "Performance Indicators and Quality Review in Australian University", in Higher Education Research and Development. 14(2):245-253, https://doi.org/10.1080/0729436950140207.

[29] Altrtwry, M Wjwyhan, A. (2006). Edart Aljwdh Alshamlh Fy M'ssat Alt'lym Al'aly Walmktbat Wmrakz Alm'lwmat. 'man: Dar Almsyrh Lltba'h Walnshr.

[30] Altwyl, A Walkwrany, F. (2007). "Emkanyt Ttbyq Edart Aljwdh Alshamlh Fy Jam't Almwsl: Drash 'la Mjmw'h Mkhtarh Mn Klyat Aljam'h". Mjlt Alrafdyn: 82 (28). 